Louisiana State University

LSU Digital Commons

\title{
Culture-independent identification of gut bacteria in fourth-instar red imported fire ant, Solenopsis invicta Buren, larvae
}

\author{
Albert Hon-Yu Lee \\ Louisiana State University and Agricultural and Mechanical College
}

Follow this and additional works at: https://digitalcommons.Isu.edu/gradschool_dissertations

Part of the Entomology Commons

\section{Recommended Citation}

Lee, Albert Hon-Yu, "Culture-independent identification of gut bacteria in fourth-instar red imported fire ant, Solenopsis invicta Buren, larvae" (2007). LSU Doctoral Dissertations. 363.

https://digitalcommons.Isu.edu/gradschool_dissertations/363

This Dissertation is brought to you for free and open access by the Graduate School at LSU Digital Commons. It has been accepted for inclusion in LSU Doctoral Dissertations by an authorized graduate school editor of LSU Digital Commons. For more information, please contactgradetd@lsu.edu. 


\title{
CULTURE-INDEPENDENT IDENTIFICATION OF GUT BACTERIA IN FOURTH-INSTAR RED IMPORTED FIRE ANT, SOLENOPSIS INVICTA BUREN, LARVAE
}

\author{
A Dissertation \\ Submitted to the Graduate Faculty of the \\ Louisiana State University and \\ Agricultural and Mechanical College \\ in partial fulfillment of the \\ requirements for the degree of \\ Doctor of Philosophy
}

in

The Department of Entomology

by

Albert Hon-Yu Lee

B.S., University of California, Riverside, 2000

M.S., University of California, Riverside, 2002

December 2007 


\section{ACKNOWLEDGEMENTS}

This project represents nearly half a decade's work in unexplored space. Many hours have been spent thinking of ways to navigate the unknown. Despite the challenges, I am thankful for the opportunities. Like the first explorers who had the chance to set foot on the top of Mount Everest or the Moon, I was given the opportunity to explore the inner space of a baby ant that has the potential to grow up to be a malicious pest. I started my journey expecting to find strange new life and civilizations and to boldly go where no entomologist has gone before. When I did not find those interesting life forms, I became upset. With time, I have learned that the journey itself can be just as rewarding as making first contact with an ant endosymbiont that does not seem to exist. My journey began with an ant research poster I presented at a scientific conference shortly after the turn of the last century.

What started off as a chat in the poster gallery in Charleston, SC has led me thousands of miles from home in pursuit of a group of bugs that like to sting tailgaters. The voyage to make first contact with the elusive endosymbiont would not have been possible without some genuinely awesome people. I would like to thank Dr. Linda Hooper-Bùi for taking me under her wings and for giving me an opportunity to study ants with equipment I thought only existed in sci-fi television. Dr. Bùi inspired me to be a good teacher and taught me that there is a right and wrong way to teach. The years in her lab has taught me a lot about science, organization, etiquette, professionalism, and the need to avoid drama like a pack of wild badgers. I am so glad she decided to visit that poster gallery in Charleston.

Good scientists are not born they are made through teaching and by example. I have the rest of my advising committee to thank for their efforts. I hope to live up to their standards of excellence as I move on in my career. My deepest gratitude to Dr. Claudia Husseneder for 
opening up her lab and for her guidance during the whole project, she was one of the main reasons I came to Baton Rouge. Her skills in molecular biology and critical thinking have no equal. Special thanks go to Drs. Huangen Ding and Frederick Enright for their instructions and advice in molecular genetics and biology. And finally Dr. Christopher Carlton for teaching me to remember that despite being awestruck with fancy sequencers and electron microscopes, I am still an entomologist. Dr. Carlton's down-to-earth explanations, advice, and encouragements helped me look at the future through a practical lens.

I was given a lot of help with this project and am very grateful for the people mentioned above however I can not forget others for their support too. The following people have my warmest gratitude: Simon Lee, Rowena Lee, Billy Wise, Huei-Yang Ho, Michael Seymour, Dr. Gabriel Aluko, Dr. Rachael Collier, Dawn Simms, Jennifer Delatte, Brandon Hill, and Ying Xiao. I will never forget you all. First contact was never made with the elusive fourth-instar red imported fire ant endosymbiont. Maybe it will reveal itself one day to an unsuspecting explorer. 


\section{TABLE OF CONTENTS}

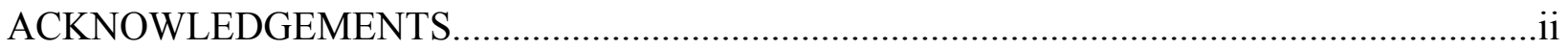

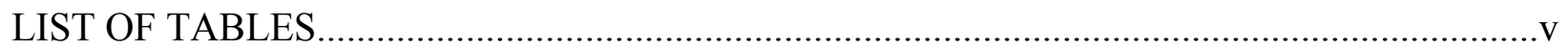

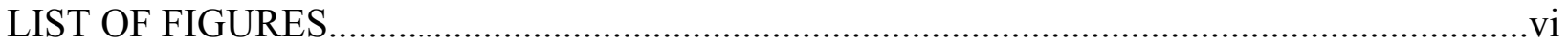

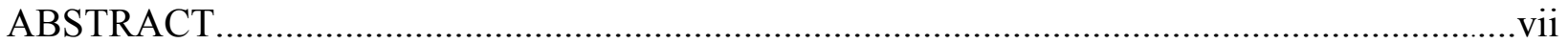

CHAPTER

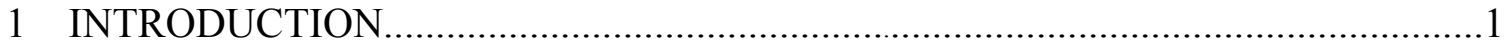

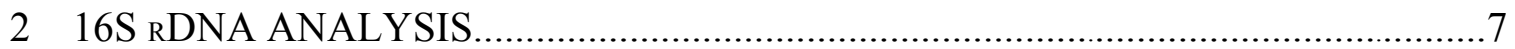

3 EIGHTY-TWO DAYS LATER - BOGALUSA REVISITED: EFFECT OF CAPTIVITY ON FIRE ANT MICROBIAL DIVERSITY ........................................33

4 EFFECT OF ANTIBIOTICS ON RED IMPORTED FIRE ANT MORTALITY ........44

5 EXAMINATION OF RED IMPORTED FIRE ANT LARVAE GUTS THROUGH

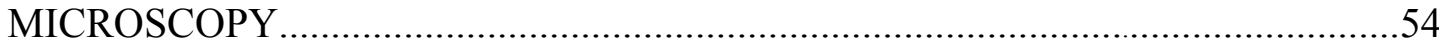

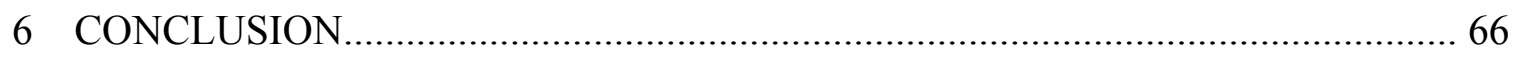

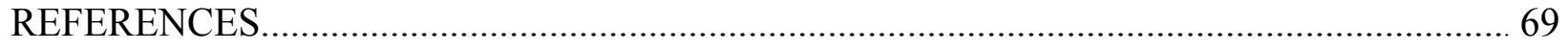

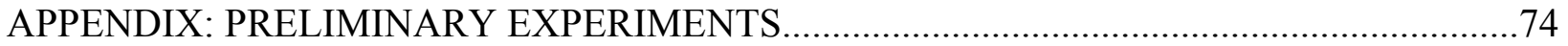

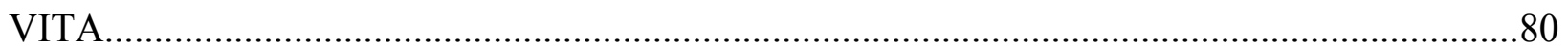




\section{LIST OF TABLES}

2.1 Summary of species found in each RIFA colony and associated estimators, percentage of estimated diversity identified, and diversity indices.

2.2 NCBI BLAST results for the 16S rRNA gene from 150 clones from the colony collected from Baton Rouge 18

2.3 NCBI BLAST results for the 16S rRNA gene from 105 clones from the colony collected from Rosepine 21

2.4 NCBI BLAST results for the 16S rRNA gene from 104 clones from the colony collected from Bogalusa. .25

2.5 Species of bacteria common to at least two RIFA colonies studied 30

3.1 NCBI BLAST results for the 16S rRNA gene from 130 clones from the lab-reared Bogalusa colony...... .36

3.2 NCBI BLAST results for the 16S rRNA gene from 104 clones from the field-fresh colony collected from Bogalusa

4.1 Red imported fire ant mortality averages and standard deviations of control and antibiotic treatments. .50

4.2 Significant differences detected with the Tukey-Kramer analysis between treatments .51 


\section{LIST OF FIGURES}

2.1 Species accumulation curves (Sobs) of all three RIFA colonies from Louisiana with 95\% confidence intervals.

2.2 Species accumulation analysis of the 16S rDNA clone library from the Baton Rouge colony

2.3 Phylogenetic affiliations of the bacteria found in the Baton Rouge colony.....

2.4 Species accumulation analysis of the 16S rDNA clone library from the Rosepine RIFA

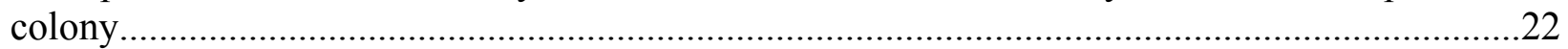

2.5 Phylogenetic affiliations of the bacteria found in the Rosepine colony..............................23

2.6 Species accumulation analysis of the $16 \mathrm{~S}$ rDNA clone library from the Bogalusa RIFA

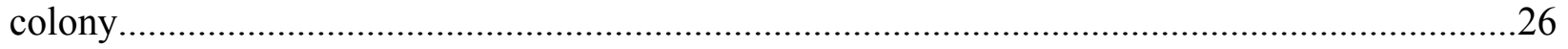

2.7 Phylogenetic affiliations of the bacteria found in the Bogalusa colony...............................27

3.1 Species accumulation analysis of the $16 \mathrm{~S}$ rDNA clone library from the lab-reared Bogalusa

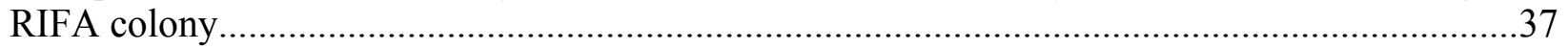

3.2 Phylogenetic affiliations of the bacteria found in the Bogalusa colony after 82 days.............39

4.1 Mortality curve of treated and untreated RIFA...........................................................48

4.2 Survivorship curve of treated and untreated RIFA....................................................49

5.1 Cross section of the foregut/midgut showing the lumen and epithelial cells.......................57

5.2 Light microscopy cross-section images of a fourth-instar larva's hindgut...........................58

5.3 Scanning electron micrograph of the foregut/midgut of a fourth-instar larva longitudinal

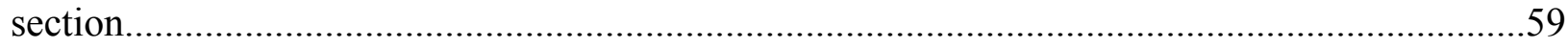

5.4 Scanning electron micrograph of the hindgut of a fourth-instar larva................................60

5.5 Scanning electron micrograph of the hindgut of a fourth-instar larva................................61

5.6 Scanning electron micrograph of the hindgut of a fourth-instar larva...............................62

5.7 Cross-section of the hindgut of a fourth-instar larva..................................................63 


\begin{abstract}
Red imported fire ants (RIFA), Solenopsis invicta Buren, are medical, urban, and agricultural pests from South America. Fourth-instar larvae are used by the colony to digest solid food and then regurgitate it for consumption by workers and queens. Larvae are an ideal source of investigations of obligate endosymbiotic bacteria possibly involved in nutrient distributions.

I attempted to first identify what bacteria species are in the guts of larvae followed by antibiotic and microscopy work to further study their roles in the ants. The composition of the bacterial community in fire ant larvae was described with culture-independent methods utilizing 16S rDNA sequencing. The 16S rRNA gene was directly amplified from mixed-population DNA of whole fire ant larval guts and cloned into Escherichia coli. Bacterial communities from three geographically separated RIFA colonies were examined. Sequenced bacterial clones from guts were determined to be predominantly from the phylum Proteobacteria and the family Enterobacteriaceae. The colony from Baton Rouge had 34 identified species, 25 identified species from the Rosepine colony, and nine from the Bogalusa colony. None of the identified bacteria were closely related to known coadapted endosymbionts from other insect species. Bacterial inventories from each location provided little evidence of common bacteria among them. Even though Klebsiella pneumoniae appeared in all three colonies, its biology suggested that it came from the environment. Obligate symbiotic bacteria, if present should be present in all larvae regardless of physical location. Antibiotic treatments indicated that ants were not affected by clearing the guts of microorganisms. Clearing of obligate symbiotic bacteria should have detrimental effects on ant mortality. Since no significant change was found, obligate symbiosis is not likely to be present between fire ants and their gut bacteria. I was unable to detect
\end{abstract}


bacteriocytes in the guts of larvae using light and electron microscopy, providing further data against an obligate symbiotic relationship.

In this study I did not detect the presence of common symbiotic bacteria in the guts of RIFA larvae among the colonies. Bacteria communities appeared to be unique to each colony and were determined by the food and environment. 


\section{CHAPTER 1}

\section{INTRODUCTION}

Symbiotic associations between organisms are a common phenomenon. These associations are described as an interaction between multiple organisms living together in intimate association (inside or on the body) or even the merging of two dissimilar organisms (Sapp, 1984). Symbiotic associations range from parasitic to transient to mutualistic (Ishikawa, 1989). A subcategory of symbiosis is known as endosymbiosis, refers to a symbiotic organism associated internally within another (e.g. intracellular, inside guts).

Insects provide a fascinating system with many examples of symbiosis with microorganisms (Bourtzis and Miller, 2003). Among insects and their associated microorganisms, a spectrum of symbiotic lifestyles ranging from obligate to transient exists. Obligate microorganisms that inhabit insects can be divided into several groups that span the spectrum of symbiotic lifestyles. The most distinctive obligate symbionts are primary symbionts that reside in specialized host cells called bacteriocytes (Moran and Baumann, 2000). These microorganisms may have coexisted for so long with the insect that they have evolved and lost their free-living survival mechanisms (Bourtzis and Miller, 2003). Obligate endosymbionts exist in specialized associations with insects. Termites for example, harbor some of the most specialized lineages of microbial endosymbionts known. Protozoans and bacteria supply the lower subterranean termites with a variety of nutrients, such as nitrogen, through fixation and recycling (Breznak et al., 1973), sugars through cellulose degradation (Breznak and Brune, 1994), and energy through acetogenic reduction of $\mathrm{CO}_{2}$ (Bignell 2000). Bark beetles (Family Curculionidae) also contain necessary mycelial fungi of the genus Entomocorticum that act as a larval nutritional symbiont (Klepzig et al., 2001). 
Obligate endosymbionts have also been found in several ant species to supplement specialized diets. Sauer et al. (2002) believed that the "Candidatus Blochmannia floridanus endosymbiont", of the ant of the species Camponotus floridanus, is most important during embryogenesis and larval development. Adult ants are able to live without their bacterial endosymbionts under laboratory conditions, and these seem to degenerate naturally over time, as observed in older queens, suggesting that the symbiosis may be of relevance during the early stages of the ants' development (Sauer et al., 2002). The omnivorous C. floridanus is also capable of feeding almost exclusively on sugary fluids due to their symbionts. Candidatus Blochmannia floridanus, which is able to supply nitrogen and sulfur compounds to its host through the host's metabolic machinery (Gil et al., 2003). Members of the genus Candidatus Blochmannia are closely related to other endosymbiotic bacteria of insects such as Buchnera of aphids, Wigglesworthia of tsetse flies, and, more distantly, Carsonella of psyllids. These bacteria form a clade contained within the family Enterobacteriaceae within the phylum Proteobacteria (Sauer et al., 2002).

Ants of the genus Tetraponera possess specialized bacterial pouches in their digestive tract. Workers are rarely seen foraging outside their nests when prey items are scarce, so Tetraponera ants are believed to depend greatly on amino acid-deficient honeydew diets (Billen and Buschinger, 2000). Certain individuals of Tetraponera are capable of feeding principally as herbivores on nitrogen-poor foods. Ribosomal RNA-encoding genes indicated that the bacteria are close relatives of Flavobacteria and Rhizobium, Methylobacterium, Burkholderia, and rootnodule bacteria capable of fixing nitrogen in Tetraponera spp. (Van Borm et al., 2002). Bacterial symbionts are also involved in recycling of nitrogen-rich metabolic waste. At the other end of the spectrum of symbiotic lifestyles are microorganisms that exist in insects simply because they were ingested from the environment. Usually no beneficial or detrimental effects between the 
insects and these microorganisms occur. For example, houseflies (Musca domestica) exhibit this type of association with the bacteria they have. Many human pathogens have been identified from houseflies. The bacteria have no visible effects on the flies but the flies vector diseases to other animals and humans where they have serious pathological effects. Banjo et al. (2005) found that these microbes were obtained from contaminated surfaces that the flies fed on. Such bacteria are of environmental origin and have a transient status in the houseflies. Similarly, cockroaches carry bacteria from their surroundings in their bodies. This is important in hospital settings where antibiotics are often used. Cockroaches pick up drug-resistant bacteria and spread them to patients by crawling on them with their contaminated bodies (Pai et al., 2004). Among ant species exists a similar example. Like cockroaches, the omnivorous pharaoh ant (Monomorium pharaonis) has become a serious pest in hospitals capable of spreading drugresistant bacteria to patients (Beatson, 1972). The following ant species, Tapinoma melanocephalum, Paratrechina longicornis, and Solenopsis saevissima have all been found to be carriers of antibiotic-resitant bacteria as well (Moreira et al., 2005). Though transient in status, these internal and external microorganisms along with their associated hosts remain important models of study in the field of pathology.

Studies of individuals belonging to Tetraponera and Camponotus resulted in the discovery and identification of coadapted endosymbionts (Jaffe et al., 2001, Sauer et al., 2002) These endosymbiotic microorganisms were found to be important in nutritional and possibly reproductive roles (Van Borm et al., 2002, Sauer et al., 2002). Certain species of Tetraponera and Camponotus can be considered herbivores since they are capable of reproduction by feeding almost exclusively on nectars (Blüthgen et al., 2003). Though high in sugar content, nectar lacks nitrogen. While Tetraponera and Camponotus may survive as primarily herbivores (Blüthgen et 
al., 2003), Red imported fire ants (RIFA), Solenopsis invicta Buren are believed to be completely omnivorous and also tend insects that secrete honey dew.

Bacteria have been cultured from RIFA fourth-instar larvae guts on nutrient, blood agar, and BHI (Peloquin and Greenberg, 2003, Li et al., 2005). However, the bacterial inventory is incomplete due to the selective nature of growth media, not all available bacteria can be grown on one type of general media. Therefore, culture independent techniques are necessary to acquire the bacterial inventory to study the microbial community. A culture-independent study aimed at analyzing the complete community of microorganisms in fourth-instar RIFA has not, to our knowledge, been previously attempted. Such a study may provide insight on an aspect of dietary needs or reproduction that may not have been detected in previous studies done with culturedependent methods (Li et al., 2005, Peloquin and Greenberg, 2003). The fourth instar larvae of RIFA are unique in that they are the only stage in the species life cycle that can digest solid foods (Vinson and Sorenson, 1986). Due to their special role in the colony, they may contain obligate nutritional microorganisms that facilitate the breakdown of nutrients processed as in studied individuals belonging to Tetraponera and Camponotus.

The need to investigate microbial communities in this species is due to the detrimental and invasive effect RIFA has on the environment, wildlife, and other invertebrates. The red imported fire ant is a medical, urban, and agricultural pest from South America. It has invaded the southern states of the U.S., California, Puerto Rico, Australia, Taiwan, and Hong Kong. Fire ants have painful stings that are a serious health concern for people living in their invaded range. It is such a successful invader due to its preference for disturbed habitats, high reproductive rates, and its ability to feed on a wide variety of food items. These features also make them successful competitors (Vinson and Greenberg, 1986). Information from my study may provide insight into their biology and could lead to research on control. 
The first steps in my investigations were to determine which microbes are present in RIFA and whether or not they are obligate (important for RIFA survival) or transient. Symbionts as biological control agents were found to be effective in the control of Chagas disease vectored by Rhodnius prolixus. The endosymbiotic organism, Rhodococcus rhodnii was genetically transformed to express an anti-trypanosomal product in the insect gut (Beard et al., 1992, Beard et al., 1998). If such obligate endosymbionts exist in RIFA then similar control technologies through symbionts may be developed to cope with this species by way of baiting for their endosymbiotic counterparts. Sustainable biological management may be possible if coadapted endosymbionts of RIFA can be characterized and targeted. It is known that RIFA require a mix of proteins and sugars as food to survive, and that adult worker ants are only able to ingest liquids or very small particles because of the constriction between their trunk and gaster. Solid foods such as insects and worms are liquefied by placing them in a depression in front of the mouth of fourth-instar larvae, which regurgitate digestive enzymes onto the food. Larvae are an ideal source for investigation of symbiotic bacteria that could be involved in nutrient distribution as they are likely to be the stage that contains obligate microorganisms that facilitate the breakdown of solid foods foraged for by adult workers. The hypothesis for the study is that RIFA fourth-instar larvae contain coadapted mutualistic bacteria in their guts.

The objective of this study was to:

1. Determine where the bacteria in the fourth-instar RIFA larvae fall in the spectrum of symbiosis and identify bacteria species common to colonies found in Louisiana.

2. Determine if bacteria inventories in RIFA will change due to food and environment.

3. Determine if clearing the gut flora of RIFA would affect ant mortality.

4. Examine the interior structures of fourth-instar larvae guts for the presence of bacteriocytes. 
The following chapters are presented in the "journal style" format. Chapters following the Introduction address each of the above objectives. Chapter two discusses the prime objective while the other chapters serve to reinforce the conclusions derived from it. Upon determining the transient nature of bacteria in RIFA larvae through molecular techniques, further support is provided by showing that diet and environment can change the bacteria inventory. Ant mortality is unaffected when bacteria are removed from the guts with broad-spectrum antibiotics. My final experiment with microscopy provides visual evidence that bacteriocytes do not exist in RIFA.

Red imported fire ants of all stages were collected from Baton Rouge and preserved in $100 \%$ alcohol as voucher specimens. These specimens can be found at the Louisiana State Arthropod Museum. 


\section{CHAPTER 2}

\section{S RDNA ANALYSIS}

\section{Introduction}

I studied the nature of the symbiotic relationship (obligate vs. transient) between fourth instar RIFA larvae and their associated gut bacteria. In order to address the question of whether the bacteria found in fourth instar RIFA larvae were closely associated with ants through coadaptation, or are merely transient.

Culture-dependent studies have already identified bacteria species (Lactococcus garviae, Staphylococcus saprophyticus, Enterococcus spp., Enterobacter spp., Kluyvera cryocrescens, Pseudomonas aeruginosa, Achromobacter xylosoxidans, Bacillus pumilus, Listeria spp., and Serratia marcescens) in RIFA fourth instar larvae from California (Peloquin and Greenberg, 2003) and Texas (Li et al., 2005). This early work showed a limited number of bacteria which are present in guts of fourth instar RIFA larvae. The limited number of cultured bacteria in their studies may be due to the fact that $>85 \%$ of known naturally occurring bacteria can not be cultured with currently available techniques (Liu et al., 1997). Culturing was also biased in that it selected for organisms that are able to grow under the chosen culture conditions. Cultureindependent molecular techniques provide an opportunity to describe microbial diversity without the need to culture live bacteria (Urakawa et al., 1999), and thus these techniques remove biases associated with culturing and provide a comparatively unbiased inventory. The most common molecular approach to identifying yet-to-be cultured bacteria was to sequence the $16 \mathrm{~S}$ rRNA gene (Liu et al., 1997). Gene sequences can then be compared to the public database GenBank through BLAST (Altschul et al., 1990) to identify the bacteria. 


\section{Materials and Methods}

Red imported fire ant colonies were collected from three areas in Louisiana and the bacterial species composition, numbers, and proportions in fourth instar larvae were determined. To determine whether symbionts were obligate and coadapted (i.e. endosymbiotic) or derived from the environment and transient, several factors were examined. The bacterial inventory of each colony was compared in order to find possible species overlaps. Phylogenetic trees constructed with DNA sequences from each identified bacterium indicated how closely related they are to each other. I expected a similar list of bacteria from each RIFA colony, similar branching and clustering between bacterial clades in the phylogenetic trees, and similar bacterial diversity and evenness in all the colonies if the majority of bacteria were obligate symbionts coadapted with the ant. I assumed coadapted obligate endosymbionts would share these traits in all of the examined colonies.

\section{Collection of Ants}

The study analyzed RIFA colonies located across the state of Louisiana. Three geographically separated RIFA colonies (Baton Rouge in East Baton Rouge Parish (30.41246, 91.19555), Rosepine in Vernon Parish (30.84611, -93.28889), and Bogalusa in Washington Parish $(30.74775,-89.88829)$ were collected from the field in the spring and summer months of 2005 and 2006. The distance between Rosepine and Bogalusa was approximately 370 kilometers, with Baton Rouge between the two cities. Ants from Baton Rouge were collected from a dirt parking lot, while ants from Rosepine were collected from a horse pasture and those from Bogalusa were collected from a pasture occupied by cows.

Soil containing fire ants and brood were collected in buckets lined with Teflon to prevent their escape. Using a technique described by Banks et al. (1981), the buckets were slowly flooded with tap water to force the ants to the soil surface. Five hundred milliliters $(\mathrm{mL})$ of water 
was added every 30 minutes until the ants formed a cluster and floated to the surface of the water. At that point the ants were placed in a plastic rearing tray lined with Teflon and furnished with a Plaster of Paris brood chamber cast inside a Petri dish. The lid of the chamber was painted black to provide a dark harborage. Plaster harborages were kept moist with a shoestring, embedded in the plaster, which absorbs added water. After the ants moved all their brood to the brood chamber, larvae were collected.

Larvae were obtained by rendering all the ants immobile with ethyl ether and placing them on black construction paper (Banks et al., 1981). Ether treatments induced workers holding the larvae to relax their jaws. The construction paper's surface was rough enough for the ants' spines to adhere to it. Once the ants were attached to the paper, it was tilted and the larvae slid off. Larvae were washed with 95\% ethanol once (Bussaban and Lumyong, 2003) and rinsed with sterile water twice.

\section{DNA Extraction and Amplification}

All available larvae from each colony were taken out for the study. Depending on the colony, twenty-five (Rosepine), fifty-four (Bogalusa), and two hundred (Baton Rouge) whole/entire larval guts were aseptically isolated on a sterile microscope slide and pooled for each colony (separately) in tubes containing $300 \mu \mathrm{l}$ of phosphate buffered saline (PBS). Insect pins dipped in $70 \% \mathrm{EtOH}$ and sterilized over a flame were used to dissect out each gut. Guts were then transferred to tubes of PBS with similarly sterilized forceps. Bacterial DNA from each colony was processed and analyzed separately. The protocol for extracting Gram-positive bacteria from the Qiagen DNeasy Tissue kit (QIAGEN, Chatsworth, CA, USA) was used to obtain bacterial DNA templates to be amplified in polymerase chain reaction (PCR). This protocol included a rigorous lysozyme treatment step that could extract DNA from both Grampositive and Gram-negative bacteria. The 16S rRNA genes were amplified with PCR using the 
universal 16S rRNA PCR primers 27F and 1492R (Lane, 1991). Each reaction contained 4-8 ng of DNA template $(1 \mu \mathrm{L})$, one microliter $(\mu \mathrm{L})$ of each primer $(0.25 \mu \mathrm{g} / \mu \mathrm{L}), 0.2 \mu \mathrm{L}$ (1 unit) of AmpliTaq polymerase (Roche Diagnostics, Alameda, CA), $10 \mu \mathrm{L}$ of $5 \mathrm{X}$ buffer (10mM $\mathrm{MgCl}_{2}$, $\mathrm{pH}$ 9.0), $31.8 \mu \mathrm{L}$ of PCR quality water, and $5 \mu \mathrm{L}$ of dNTPs $(2.5 \mathrm{mM})$. The dNTPs were added after a $3 \min 80^{\circ} \mathrm{C}$ hot-start. Negative controls, which contained no DNA templates, were used in every reaction to check for contamination. An Invitrogen PCR Optimization Kit (Invitrogen, Carlsbad, CA) was used to determine the most effective cycle and conditions for the reaction. All PCR reactions were conducted using an MJ Research PTC-200 Peltier Thermal Cycler. The cycle had an initial denaturation step $\left(94^{\circ} \mathrm{C}, 1 \mathrm{~min}\right), 25$ cycles of annealing $\left(94^{\circ} \mathrm{C}, 1 \mathrm{~min}\right.$ and $\left.55^{\circ} \mathrm{C}, 2 \mathrm{~min}\right)$ and extension $\left(72^{\circ} \mathrm{C}, 3 \mathrm{~min}\right)$ and a final extension step $\left(72^{\circ} \mathrm{C}, 7 \mathrm{~min}\right)$. PCR products were purified with Qiagen's Qiaquick Purification Kit (QIAGEN, Chatsworth, CA, USA).

\section{Cloning}

Clone libraries of individual 16S rDNA PCR products were made using Invitrogen's TOPO cloning kit. A dilution series of transformed E. coli cells containing the M13 plasmid with ligated 16S rRNA gene inserts were plated on Lauria-Bertani agar plates with $50 \mu \mathrm{g} / \mathrm{ml}$ of kanamycin and $40 \mu 1$ of $40 \mathrm{mg} / \mathrm{ml} \mathrm{Xgal} \mathrm{spread} \mathrm{on} \mathrm{the} \mathrm{surface} \mathrm{(Sigma-Aldrich,} \mathrm{St.} \mathrm{Louis,} \mathrm{MO).}$ The plates were then incubated at $37^{\circ} \mathrm{C}$ for $24 \mathrm{~h}$, followed by blue-white screening. Between 104 and 150 white colonies (cells with 16S rRNA gene ligated to M13 plasmid) were selected randomly per colony. Plasmid DNA of each clone containing the amplified 16S rRNA gene PCR products were obtained by boiling the E. coli cells at $98^{\circ} \mathrm{C}$ for $10 \mathrm{~min}$ and centrifuging at 13,200 rpm for 1 min. The 16S rRNA gene fragments in the plasmid were amplified through PCR using, M13F and M13R primers (described in manual of cloning kit), which bound to the flanking sequences in the cloning vectors. The M13 PCR utilized the same cycle described earlier and the products were purified with the Qiagen's Qiaquick Purification Kit. 


\section{DNA Sequencing}

A USB Thermo Sequenase Cycle Sequencing Kit (USB Corporation, Cleveland, OH) was used in conjunction with the Li-Cor 4300 DNA Analyzer (Li-Cor Corporation, Lincoln, NE) to sequence PCR products. The PCR products were bidirectionally sequenced with $16 \mathrm{~S}$ rRNA gene PCR primers (see above) and contiguous sequences of near full length of the 16S rRNA (1200 bp-1400 bp) gene were assembled utilizing Li-Cor's E-seq software package and Vector NTI version 7 (Invitrogen). Sequences were then compared to the GenBank database through BLAST (Basic Local Alignment Search Tool, Altschul et al., 1990). If a sample matched a sequence in GenBank at $\geq 99 \%$ an exact species match was assumed. If a sample matched a sequence at $\geq 97 \%$, but $<99 \%$ it was assumed to be a novel species in the highest matching genus (Drancourt et al., 2000). Discovered novel species were submitted to GenBank and accession numbers acquired.

\section{$\underline{\text { Phylogenetic Trees }}$}

Molecular Evolutionary Genetics Analysis (MEGA) version 3.1 (Kumar et al., 2004) was used to align sequences and to construct neighbor-joining bootstrap (1000 samplings) phylogenetic trees utilizing Kimura's two-parameter model (Nei and Kimura, 2000). Kimura's two-parameter model corrected for multiple mutations, which took into account transitional and transversional substitution rates, and assumed that the four nucleotide frequencies were the same and that rates of substitution did not vary among sites. Alignment parameters were based on recommendations by Hall (2001) and were set with the following values: pairwise parameters with gap opening penalty $=10$ and gap extension penalty $=0.1$, multiple parameters with gapopening $=10$, and gap-opening penalty $=0.2$. These settings were based on recommendations by Hall (2001). Calculation parameters for constructing trees were set to 1000 bootstrap replicates with CNI level=1 and initial tree settings configured to Random addition (10 reps). The 
aforementioned were the default parameters assigned by MEGA. Trees contained bacteria species found in the ant guts of my study, type strains of related bacteria species, bacteria identified in leafcutter ants, tsetse flies, aphids, tree ants, and sequences of described bacteria that closely matched uncultured strains of my study. The trees only contained the topology of the species branches. Estimated sequence divergences were not included, because the sequences were very similar within clusters. If shown, the branches would be tightly packed together and resolution would be minimal. Two tree building methods were utilized for the study- the maximum parsimony method and the neighbor-joining method. The purpose of using two models was to confirm the robustness of generated trees. Maximum parsimony method constructed the optimal tree by utilizing the fewest base changes (mutations) exhibited by the data, while the neighbor-joining method constructed a tree with the smallest sum of branch lengths and did not assume all the lineages evolve at the same rate (Saitou and Nei, 1987). Very few differences between the placements of branches in relation to each other were found; therefore only the neighbor-joining trees with bootstrap values were shown in the figures. Species Accumulation Curves and Estimations of Species Diversity (Rarefaction Analysis)

EstimateS (Colwell, 1994-2001) was used to generate observed species accumulation curves, averaged over 1000 randomizations, for the data sets from each colony. The curves plotted the number of observed-species $\left(\mathrm{S}_{\mathrm{obs}}\right)$ as a function of the number of clones sequenced utilizing the sample-based Mao Tau method (Colwell et al., 2004). I used four estimators (Chao1, Jack1, Ace, and ICE) for expected species richness to calculate expected values of diversity and two diversity indices to determine which colony was the most diverse. The curves and estimators were meant to show how similar the number of observed species was to the estimated richness. Rare-isolate based Chaol and first-order jackknife techniques were used to estimate the actual number of species in each colony based on singleton and doublet species, 
respectively (Chao, 1984, Walther and Morand, 1998). Rather than simply analyze the samples with an emphasis on rare species, the abundance coverage estimator (ACE) considered the overall abundance of species in a sample. The last model utilized was the incidence-based coverage estimator (ICE) model, which considered both frequent and infrequent species (Brose et al., 2003). Estimators and their $95 \%$ confidence intervals were used to calculate the percentage of observed species richness based on the number of species identified. Species diversity of each RIFA colony was analyzed according to richness (Shannon index, range 0 to 5 for biological systems) and evenness (1-Simpson index, range 0 to 1 ) with the EstimateS program.

\section{Results}

Colonies with the lowest and highest number of larvae (Rosepine and Baton Rouge, respectively) were not significantly different from each other in terms of numbers of observed bacterial species; while the intermediate colony, Bogalusa, had the lowest number of identified bacteria (Figure 2.1). Significant similarities and differences were determined based on $95 \%$ confidence interval overlaps. An evaluation of the sampling effort using the Chaol model was performed. Analysis of the first colony (Baton Rouge) suggested that after approximately 100 clones, additional sampling would not affect the number of species found since the curve had leveled off (Hughes et al., 2001) (Figure 2.2). What remained were singletons that may be tough to acquire due to the numbers of the more common species. Chao estimators were interpolated based on the sample, so they were only as good as the sample. The other two colonies were sequenced up to a few more than 100 clones due to results from Baton Rouge colony.

\section{Colony 1: Baton Rouge, Louisiana}

I detected 34 bacteria species, identified from 150 clones in the Baton Rouge colony. This colony was the most diverse of all three colonies (Shannon index: $\mathrm{H}=2.93,1$ - Simpson 


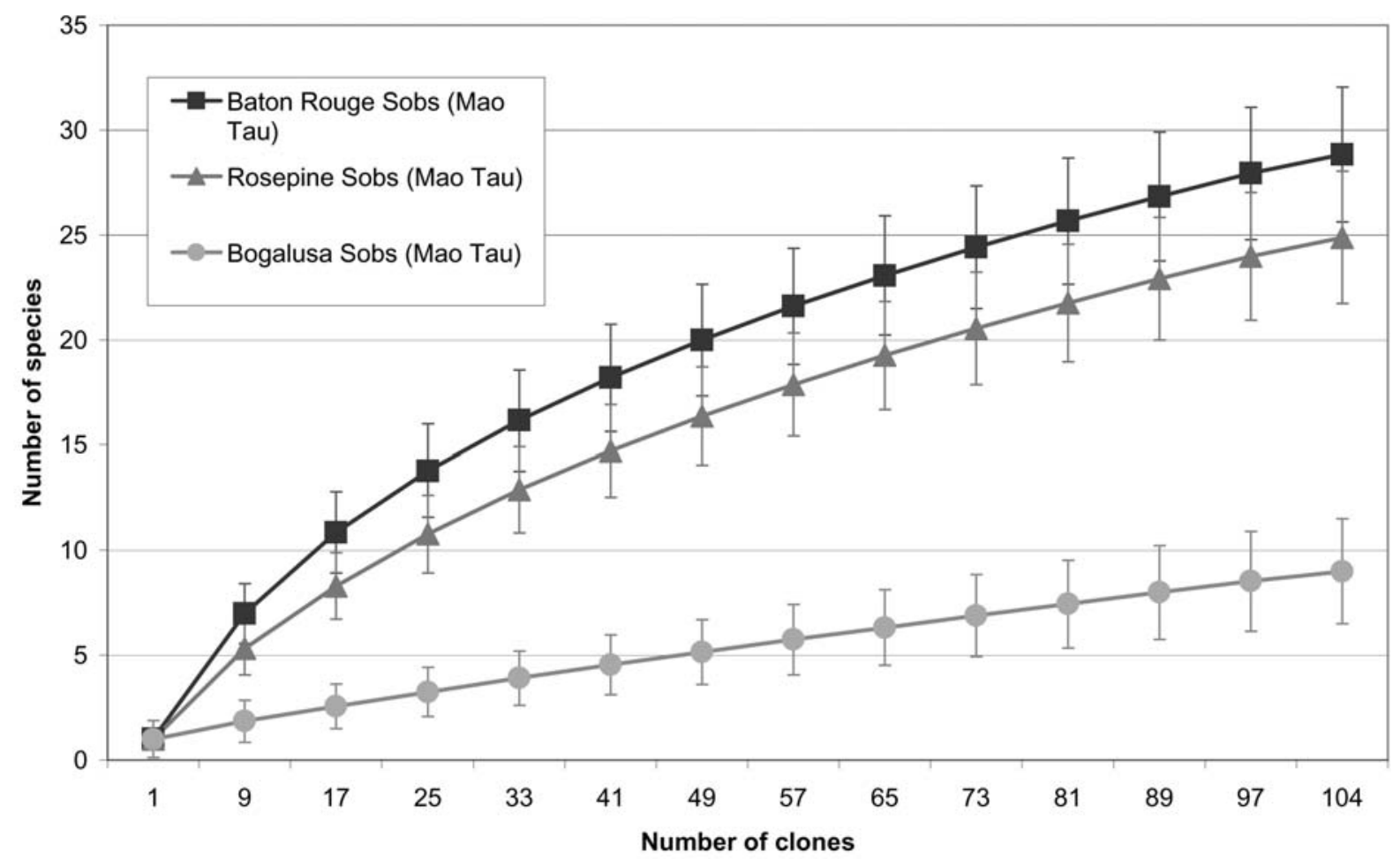

Figure 2.1. Species accumulation curves (Sobs) of all three RIFA colonies from Louisiana with $95 \%$ confidence intervals. The rarefaction curves plotted the number of observed species (Sobs) as a function of the number of clones, computed with EstimateS. Overlap of the confidence intervals indicated that species richness is not significantly different between the Baton Rouge and Rosepine colonies, which represent the highest number and lowest number of larvae used in the study, respectively. 


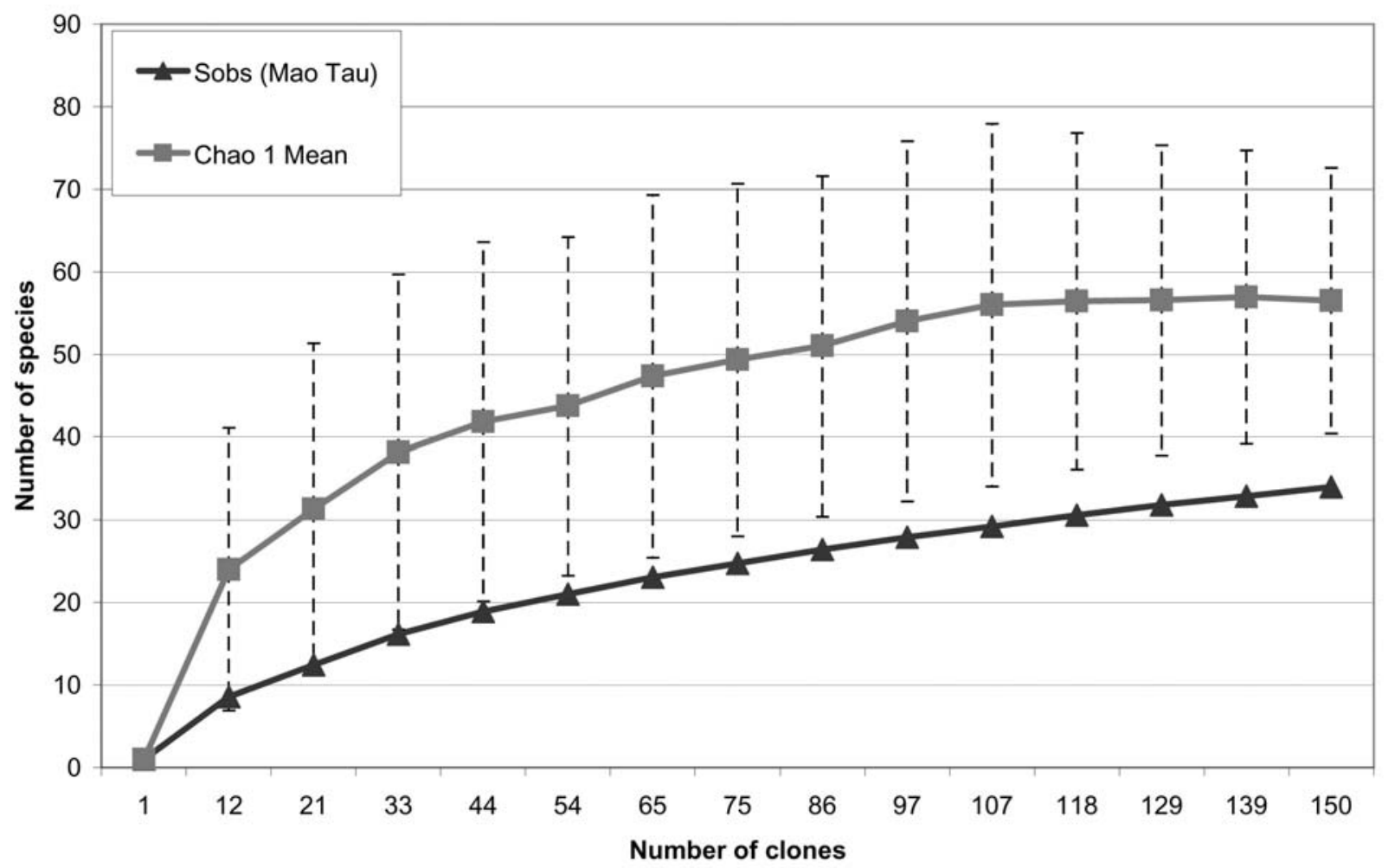

Figure 2.2. Species accumulation analysis of the 16S rDNA clone library from the Baton Rouge RIFA colony. The rarefaction curve plotted the number of observed species (Sobs) as a function of the number of clones, computed with EstimateS. The Chaol estimator for species richness (after 1,000 randomizations) was plotted with its 95\% confidence interval. At the level point (107 samples) the Chaol estimate of the number of species does not increase with the number of sampled clones (Hughes et al., 2001). 
index: $1-\mathrm{D}=0.93$ indicated that two individuals picked at random from this community would be different species in $93 \%$ of all cases). The majority of bacteria (97\%) were from the phylum Proteobacteria and family Enterobacteriaceae with only two clones from family Moraxellaceae (Acinetobacter sp. LUH1470 and an unidentified bacterial strain). Phylum Firmicutes and family Streptococcaceae had one representative (Lactococcus lactis SL3). Dominant species (\%) were all uncultured bacteria (family Enterobacteriaceae) first identified in environmental samples. Table 2.1 summarizes all the results from the utilized models, diversity indices, and percentage of identified richness from all the studied RIFA colonies. The richness estimator Chaol indicated that between $47-84 \%$ of the actual bacterial richness was identified. The percentage range was obtained by dividing the number of unique species found by the lower and upper bounds of the Chao1 estimator at a $95 \%$ confidence interval, which encompassed the ranges of the other three estimators. Rare-species based estimator Jack1 indicated that between $65-75 \%$ of the bacterial richness was identified. Both the ACE and ICE estimators indicated that about $61-64 \%$ of the bacterial richness was identified. The rarefaction analysis of the 16S rRNA gene clone library is presented in Figure 2.2. Table 2.2 summarizes the results of the 16S rRNA gene sequence of the Baton Rouge colony clones in comparison to GenBank. Six novel species were found in the Baton Rouge colony.

Bacteria from this colony were not closely related to the endosymbionts of carpenter ants, aphids, or tsetse flies, which form a unique and well-supported branch in the phylogenetic tree (Figure 2.3). Tree ants (Tetraponera spp.) symbionts were found in neighboring clades with Acinetobacter and Lactococcus species. Bacteria from RIFA larvae formed clusters with bacteria species of the same genus but beyond that point, resolution in the branches became weakly supported overall (bootstrap values $<50$ ). 
Table 2.1. Summary of species found in each RIFA colony and associated estimators, percentage of estimated diversity identified, and diversity indices. $(\mathrm{SD}=$ standard deviation, $\%$ found $=$ percentage of community identified based on a specific estimator).

\begin{tabular}{lccc}
\hline Colony & Baton Rouge & Rosepine & Bogalusa \\
\hline Larvae & 200 & 25 & 34 \\
Clones & 150 & 105 & 104 \\
Species & 34 & 25 & 9 \\
Chao1 & 56.50 & 41.90 & 30.00 \\
Chao1 SD & 16.09 & 12.72 & 17.23 \\
\% Found-Chao1 & $47-84$ & $46-85$ & $19-70$ \\
Jack1 & 48.90 & 37.90 & 15.90 \\
Jack1 SD & 3.70 & 3.40 & 2.50 \\
\% Found-Jack1 & $65-75$ & $61-72$ & $49-67$ \\
ACE & 54.49 & 47.22 & 44.80 \\
ACE SD & 1.40 & 2.08 & 3.02 \\
\% Found-ACE & $61-64$ & $51-55$ & $19-22$ \\
ICE & 54.35 & 47.13 & 42.69 \\
ICE SD & 1.40 & 2.07 & 2.84 \\
\% Found-ICE & $61-64$ & $51-55$ & $20-23$ \\
Shannon Index (H) & 2.90 & 2.20 & 0.50 \\
1-Simpson Index (1-D) & 0.93 & 0.78 & 0.19 \\
\hline
\end{tabular}


Table 2.2. NCBI BLAST results for the $16 \mathrm{~S}$ rRNA gene from 150 clones from the colony collected from Baton Rouge. The name, accession numbers, closest matches in GenBank, and the number of clones identified to the species (category) are displayed.

\begin{tabular}{|c|c|c|c|}
\hline Closest match in GenBank & Accession\# & $\begin{array}{l}\% \text { identity to } \\
\text { closest match }\end{array}$ & $\begin{array}{l}\text { Number } \\
\text { of clones }\end{array}$ \\
\hline Uncultured bacterium clone p-2009-s959-5 & AF371851 & $>99 \%$ & 23 \\
\hline Uncultured bacterium clone LB1B7 & AY186083 & $>99 \%$ & 21 \\
\hline Uncultured bacterium clone 1013-1-CG30 & AY532549 & $>99 \%$ & 20 \\
\hline Klebsiella pneumoniae AU1496 & AY043391 & $>99 \%$ & 10 \\
\hline Citrobacter werkmanii CDC 87658 & AF025373 & $>99 \%$ & 9 \\
\hline Enterobacter asburiae ATCC 35953 & АВ004744 & $>99 \%$ & 7 \\
\hline Bacterium KA55 & AY345447 & $>99 \%$ & 7 \\
\hline Klebsiella sp. MLO-2 & AY827578 & $>99 \%$ & 5 \\
\hline Rainbow Trout Intestinal bacterium T92 & AY374105 & $>99 \%$ & 5 \\
\hline Morganella morganii CPD30 & AY464464 & $>99 \%$ & 5 \\
\hline Uncultured bacterium clone Phe 50 & AF534213 & $>99 \%$ & 4 \\
\hline Enterobacter aerogenes 548 & AF395913 & $>99 \%$ & 3 \\
\hline Klebsiella oxytoca SB71 & AJ871856 & $>99 \%$ & 3 \\
\hline Proteobacterium Core-2 & AB111105 & $>99 \%$ & 3 \\
\hline Acinetobacter sp. LUH1470 & AJ301676 & $>99 \%$ & 2 \\
\hline Pantoea agglomerans 86350 & AF157688 & $>99 \%$ & 2 \\
\hline Unidentified Gamma Proteobacterium HTC042 & AB010848 & $>99 \%$ & 2 \\
\hline Uncultured bacterium clone p-2172-s959-3 & AF371852 & $>99 \%$ & 2 \\
\hline Citrobacter sp. genomospecies 11 & AF025369 & $>99 \%$ & 1 \\
\hline Enterobacter dissolvens ATCC 23373 & EDZ96079 & $>99 \%$ & 1 \\
\hline Obesumbacterium proteus ATCC 12841 & AJ233422 & $>99 \%$ & 1 \\
\hline Pantoea agglomerans SP1 & AF199029 & $>99 \%$ & 1 \\
\hline Uncultured Enterobacteriaceae bacterium ER-9 & AB114621 & $>99 \%$ & 1 \\
\hline Enterobacter cloacae CR1 & AY787819 & $>99 \%$ & 1 \\
\hline Uncultured bacterium Amplicon K & AJ487023 & $>99 \%$ & 1 \\
\hline Uncultured bacterium clone $\mathrm{O} 16$ & AY376693 & $>99 \%$ & 1 \\
\hline Uncultured bacterium clone $\mathrm{O} 39$ & AY376707 & $>99 \%$ & 1 \\
\hline Lactococcus lactis SL3 & AY675242 & $>99 \%$ & 1 \\
\hline Uncultured bacterium clone $040905 \mathrm{~S} 103$ & EF153301 & $100 \%$ & 1 \\
\hline Uncultured bacterium clone $040905 \mathrm{~S} 141$ & EF153302 & $100 \%$ & 1 \\
\hline Uncultured bacterium clone $040905 \mathrm{~S} 27$ & EF153297 & $100 \%$ & 1 \\
\hline Uncultured bacterium clone $040905 \mathrm{~S} 70$ & EF153298 & $100 \%$ & 1 \\
\hline Uncultured bacterium clone $040905 \mathrm{~S} 86$ & EF153299 & $100 \%$ & 1 \\
\hline Uncultured bacterium clone $040905 \mathrm{~S} 95$ & EF153300 & $100 \%$ & 1 \\
\hline
\end{tabular}




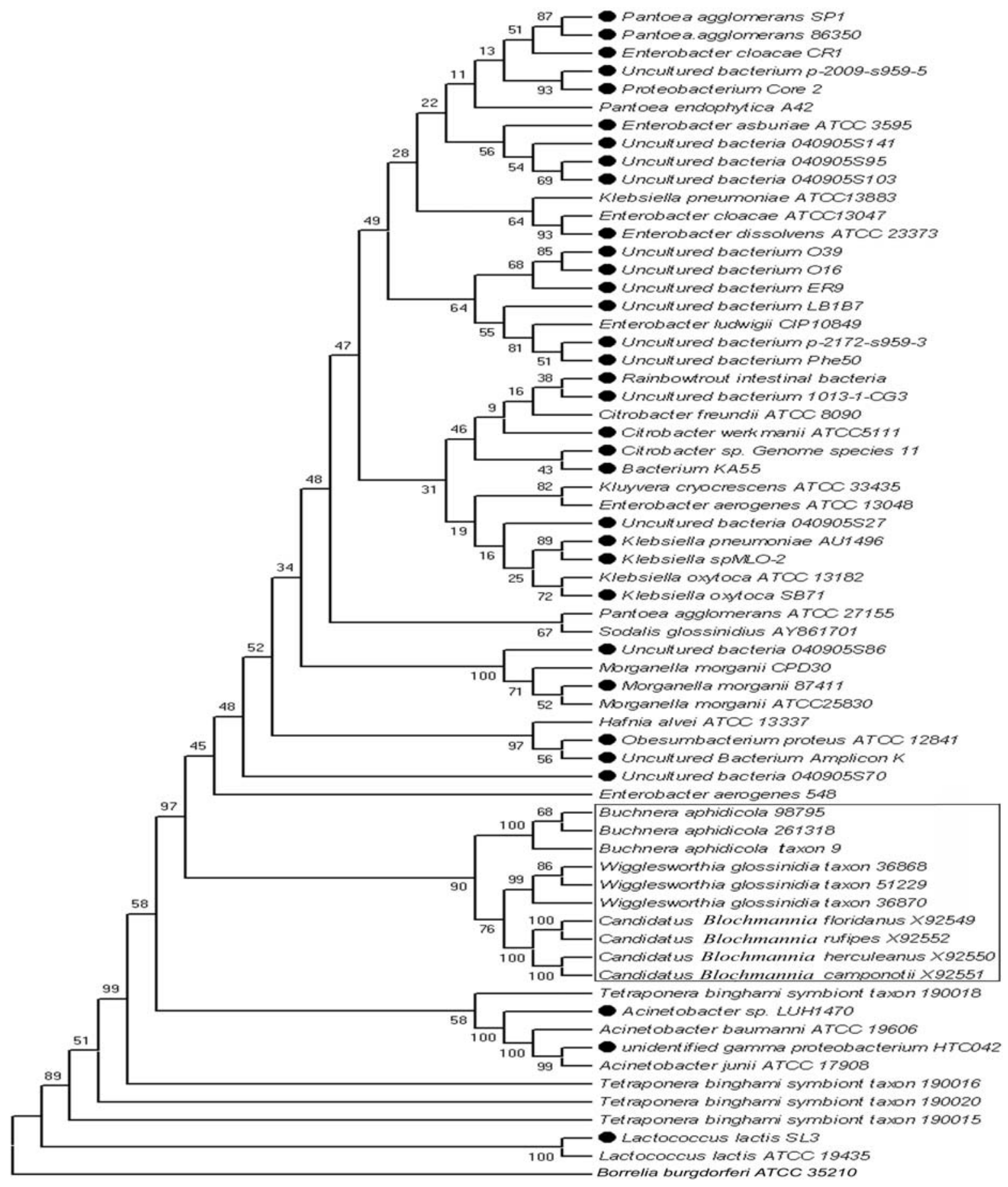

Figure 2.3. Phylogenetic affiliations of the bacteria found in the Baton Rouge colony. Type strains associated with the identified bacteria along with symbionts found in carpenter ants, tree ants, aphids, and tsetse flies are included in the tree. Borrelia burgdorferi is included in the tree as the outgroup. Only the topology of the tree and bootstrap values are shown. Estimated sequence divergences were not included. The black circles represent species that were actually found in this study. The species found in carpenter ants, aphids, and tsetse flies are boxed in to illustrate that they form a strongly supported cluster out of all the other species. 


\section{Colony 2: Rosepine, Louisiana}

I detected 25 bacteria species, identified from 105 clones in the Rosepine colony. Of the three colonies, this was intermediate in terms of bacteria species diversity (Shannon index: $\mathrm{H}=$ 2.24, Simpson index: $1-\mathrm{D}=0.78)$. The majority of bacteria $(84 \%)$ were from phylum Proteobacteria and family Enterobacteriaceae similar to the Baton Rouge colony. Several clones belonged to the family Burkholderiaceae (Burkholderia cepacia ATCC 49709, Burkholderia cepacia RRE5, and Burkholderia sp. CBPB-CHS). Two species belonged to the phylum Firmicutes and family Clostridiaceae (Rosepine isolate 8, and Rosepine isolate 27). The dominant species (\%) was Providencia stuartii. Table 2.3 summarizes results of the $16 \mathrm{~S}$ rRNA gene sequence of the Rosepine colony clones in comparison to GenBank. Note that the dominant species found in the Baton Rouge study was not found at the Rosepine site. Seven novel species were found in the Rosepine colony.

Rare-species, richness-based estimator Chao1 indicated that between $46-85 \%$ of the estimated bacterial richness was identified. Chao1 95\% confidence interval encompassed the ranges of the other three estimators as it did in the Baton Rouge colony above. Jack1 indicated that between $61-72 \%$ of the bacterial richness was identified. Both ACE and ICE estimators indicated that about $51-64 \%$ of bacterial richness was identified. Rarefaction analysis of the $16 \mathrm{~S}$ rRNA gene clone library is presented in Figure 2.4. The number of bacteria identified from the Rosepine colony was not significantly different from the Baton Rouge colony (Figure 2.1); their confidence intervals overlapped with each other. Much like the phylogenetic tree with the Baton Rouge data, the bacteria from Rosepine were not closely affiliated with the coadapted symbionts from other insects (Figure 2.5). Endosymbionts found in other insects (aphids, tsetse flies, and carpenter ants) formed an exclusive clade. 
Table 2.3. NCBI BLAST results for the 16S rRNA gene from 105 clones from the colony collected from Rosepine. The name, accession numbers, closest matches in GenBank, and the number of clones identified to the species (category) are displayed.

\begin{tabular}{llll}
\hline Closest match in GenBank & Accession\# & $\begin{array}{l}\text { \% identity to } \\
\text { closest match }\end{array}$ & $\begin{array}{l}\text { Number } \\
\text { of clones }\end{array}$ \\
\hline Providencia stuartii ATCC 29914 & AF008581 & $>99 \%$ & 47 \\
Uncultured Bacterium Clone f4s2 & DQ068792 & $>99 \%$ & 9 \\
Burkholderia cepacia ATCC 49709 & AY741349 & $>99 \%$ & 7 \\
Uncultured Bacterium Clone s4w18-5 & DQ068915 & $>99 \%$ & 6 \\
Pantoea endophytica A42 & AF130914 & $>99 \%$ & 5 \\
Uncultured bacterium clone 070505S27 & EF153303 & $100 \%$ & 4 \\
Enterobacter cloacae CR1 & AY787819 & $>99 \%$ & 3 \\
Proteobacterium Core-2 & AB111105 & $>99 \%$ & 2 \\
Uncultured bacterium clone O16 & AY376693 & $>99 \%$ & 2 \\
Klebsiella oxytoca SB71 & AJ871856 & $>99 \%$ & 2 \\
Uncultured Bacterium clone fh12 & DQ303267 & $>99 \%$ & 2 \\
Enterobacter sp. pptphilum & AY596467 & $>99 \%$ & 2 \\
Uncultured Bacterium Clone s4w18-11 & DQ068913 & $>99 \%$ & 1 \\
Uncultured Bacterium 6s27 & DQ068854 & $>99 \%$ & 1 \\
Klebsiella pneumoniae AU1496 & AY043391 & $>99 \%$ & 1 \\
Enterobacter aerogenes s21 & DQ124676 & $>99 \%$ & 1 \\
Enterobacter asburiae ATCC 35953 & AB004744 & $>99 \%$ & 1 \\
Burkholderia sp. CBPB-CHS taxon 258964 & AY640617 & $>99 \%$ & 1 \\
Burkholderia cepacia RRE5 & AY946011 & $>99 \%$ & 1 \\
Uncultured bacterium clone 070505S8 & EF153304 & $100 \%$ & 1 \\
Uncultured bacterium clone 070505S95 & EF153308 & $100 \%$ & 1 \\
Uncultured bacterium clone 070505S2 & EF153305 & $100 \%$ & 1 \\
Uncultured bacterium clone 070505S135 & EF153306 & $100 \%$ & 1 \\
Uncultured bacterium clone 070505S10 & EF153307 & $100 \%$ & 1 \\
Uncultured bacterium clone 070505S129 & EF153309 & $100 \%$ & 1 \\
\hline & & & \\
\hline
\end{tabular}




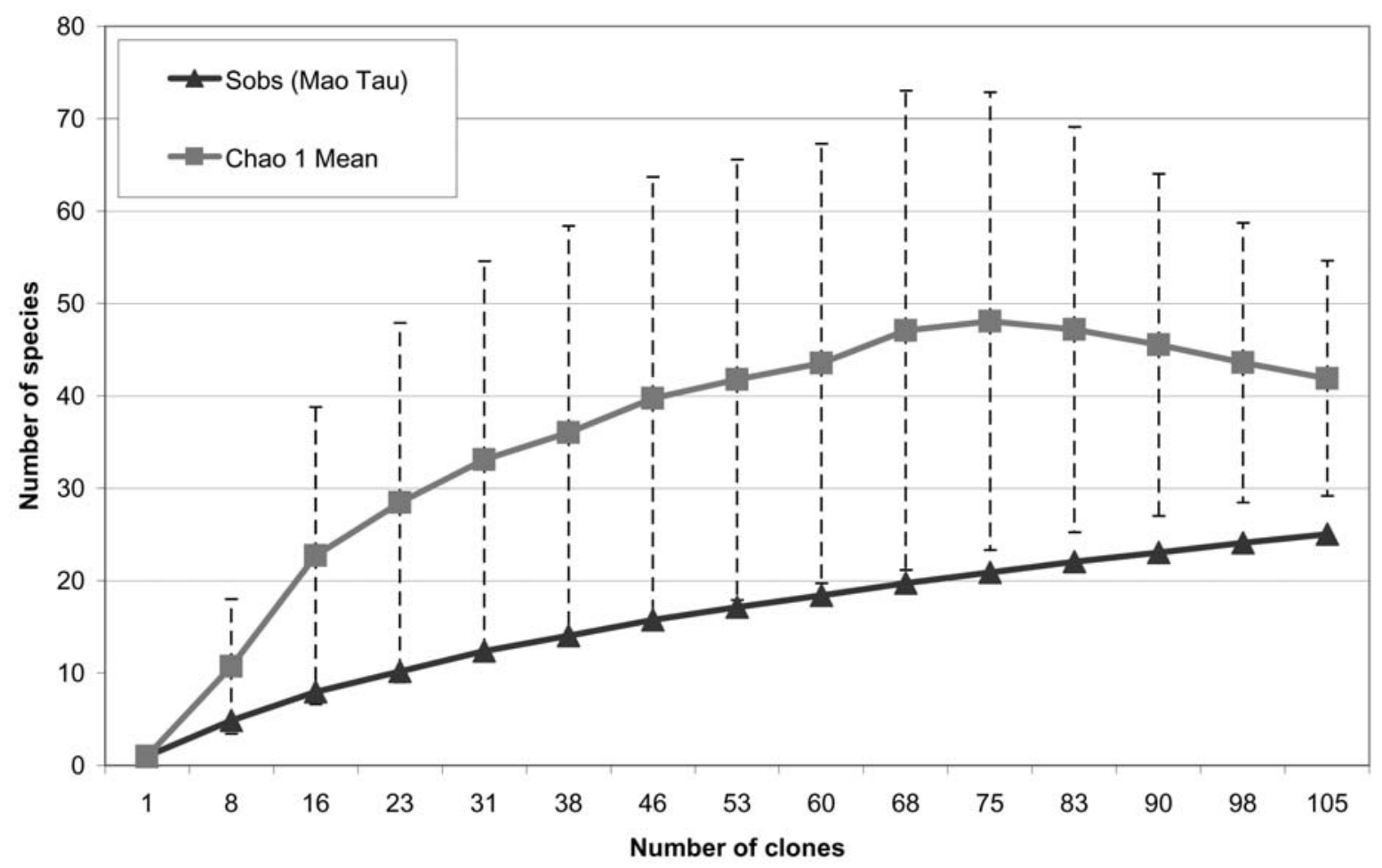

Figure 2.4. Species accumulation analysis of the $16 \mathrm{~S}$ rDNA clone library from the Rosepine RIFA colony. The rarefaction curve plotted the number of observed species (Sobs) as a function of the number of clones, computed with EstimateS. The Chaol estimator for species richness (after 1,000 randomizations) was plotted with its 95\% confidence interval. The estimator curve started descending near the end, which indicated that the estimated Chaol diversity values may be an overestimate (Hughes et al., 2001). 


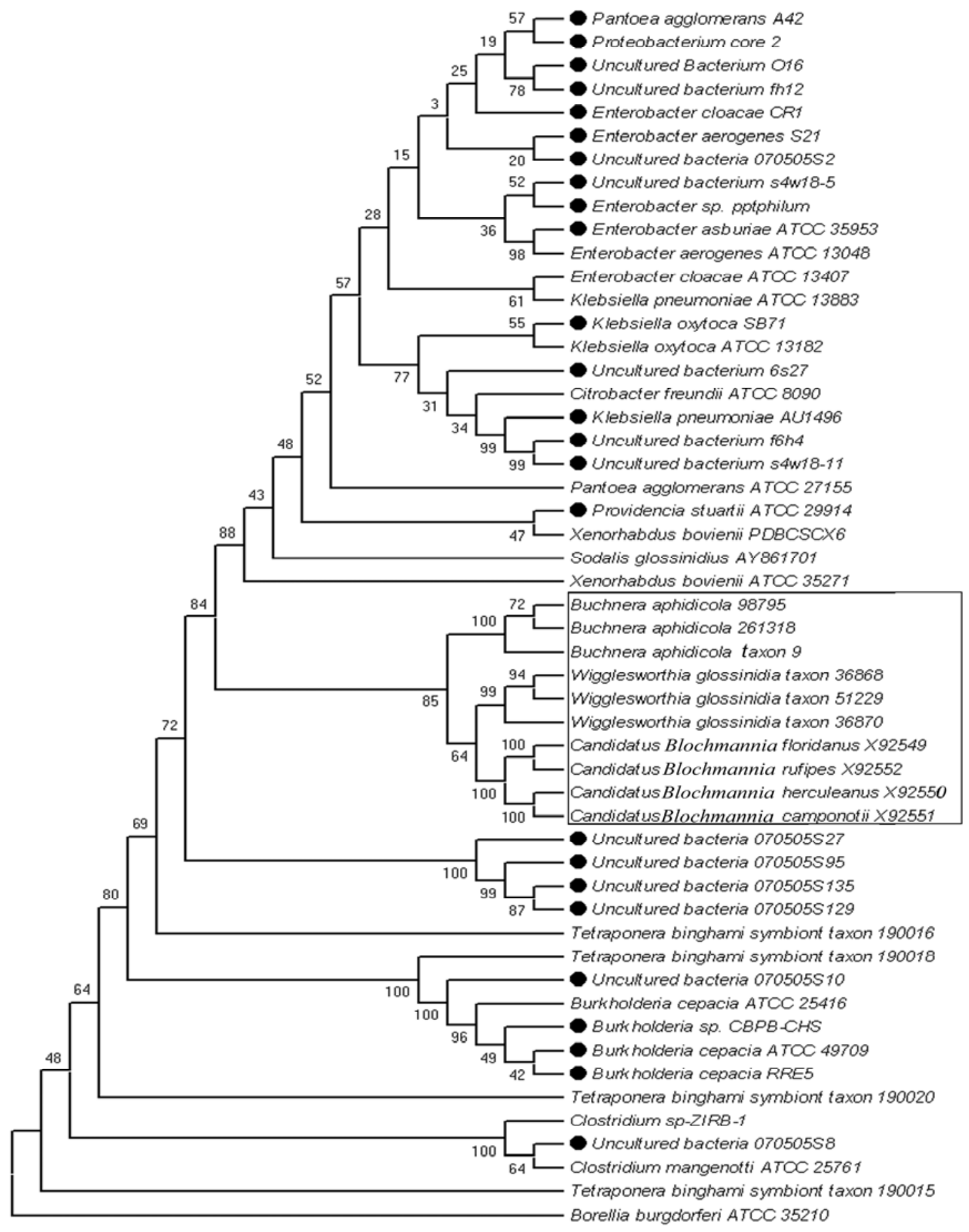

Figure 2.5. Phylogenetic affiliations of the bacteria found in the Rosepine colony. Type strains associated with the identified bacteria along with symbionts found in carpenter ants, tree ants, aphids, and tsetse flies are included in the tree. Borrelia burgdorferi is included in the tree as the outgroup. Only the topology of the tree and bootstrap values are shown. Estimated sequence divergences were not included. The black circles represent species that were actually found in this study. The species found in carpenter ants, aphids, and tsetse flies are boxed in to illustrate that they form a strongly supported cluster out of all the other species. 


\section{Colony 3: Bogalusa, Louisiana}

I detected nine bacteria species identified from 104 clones in the Bogalusa colony. Of all three colonies, the Bogalusa colony was least diverse in terms of bacteria species (Shannon index: $H=0.51$, Simpson index: $1-D=0.19)$. Bacteria were all of the phylum Proteobacteria and family Enterobacteriaceae. The dominant species was uncultured bacterium f4s 2 , first identified in ant lions (Dunn and Stabb, 2005). Table 2.4 summarizes the results of the 16S rRNA gene sequences of the Bogalusa colony clones in comparison to GenBank.

Richness estimator Chaol indicated that between $19-70 \%$ of the overall bacterial richness was identified (Chao1). Again the Chao1 95\% confidence interval encompassed the ranges of the other three estimators. Jack1 indicated that between $49-67 \%$ of the bacterial richness was identified. Both ACE and ICE estimators indicated that about $19-23 \%$ of the bacterial richness was identified.

Rarefaction analysis of the $16 \mathrm{~S}$ rRNA gene clone library for the Bogalusa colony is presented in Figure 2.6. Not enough clones were analyzed in this portion of the study according to the Chaol model since the estimator did not reach a steady state at the end of the sampling. The curve continued to increase, indicating that continued sampling will detect a higher species number. As was observed in the aforementioned two colonies, the phylogenetic tree showed the same monophyletic cluster formed by endosymbiotic bacteria found in other insects (Figure 2.7).

\section{Discussion}

My study successfully inventoried bacteria in fourth-instar RIFA larvae guts in Southern Louisiana. The majority of the bacteria identified in the RIFA colonies were of the phylum Proteobacteria and the family Enterobacteriaceae. My results suggested that the identified bacteria are transient organisms in the RIFA gut and are native to the soil or the guts of animals. 
Table 2.4. NCBI BLAST results for the $16 \mathrm{~S}$ rRNA gene from 104 clones from the colony collected from Bogalusa. The name, accession numbers, closest matches in GenBank, and the number of clones identified to the species (category) are displayed.

\begin{tabular}{llll}
\hline Closest match in GenBank & Accession\# & $\begin{array}{l}\% \text { identity to } \\
\text { closest match }\end{array}$ & $\begin{array}{l}\text { Number } \\
\text { of clones }\end{array}$ \\
\hline Uncultured bacterium f4s2 & DQ068792 & $>99 \%$ & 94 \\
Bacterium 2-4 & DQ163943 & $>99 \%$ & 3 \\
Kluyvera cryocrescens 27 & AY946284 & $>99 \%$ & 1 \\
Pseudomonas fluorescens OST-5 & DQ439976 & $>99 \%$ & 1 \\
Acinetobacter sp. DSM 590 & AS16SRRNB & $>99 \%$ & 1 \\
Serratia marcescens KRED & AB061685 & $>99 \%$ & 1 \\
Klebsiella pneumoniae 573 & AY830396 & $>99 \%$ & 1 \\
Serratia marcescens CPO1(4) & SMA296308 & $>99 \%$ & 1 \\
Uncultured bacterium f6s10 & DQ068816 & $>99 \%$ & 1 \\
\hline
\end{tabular}




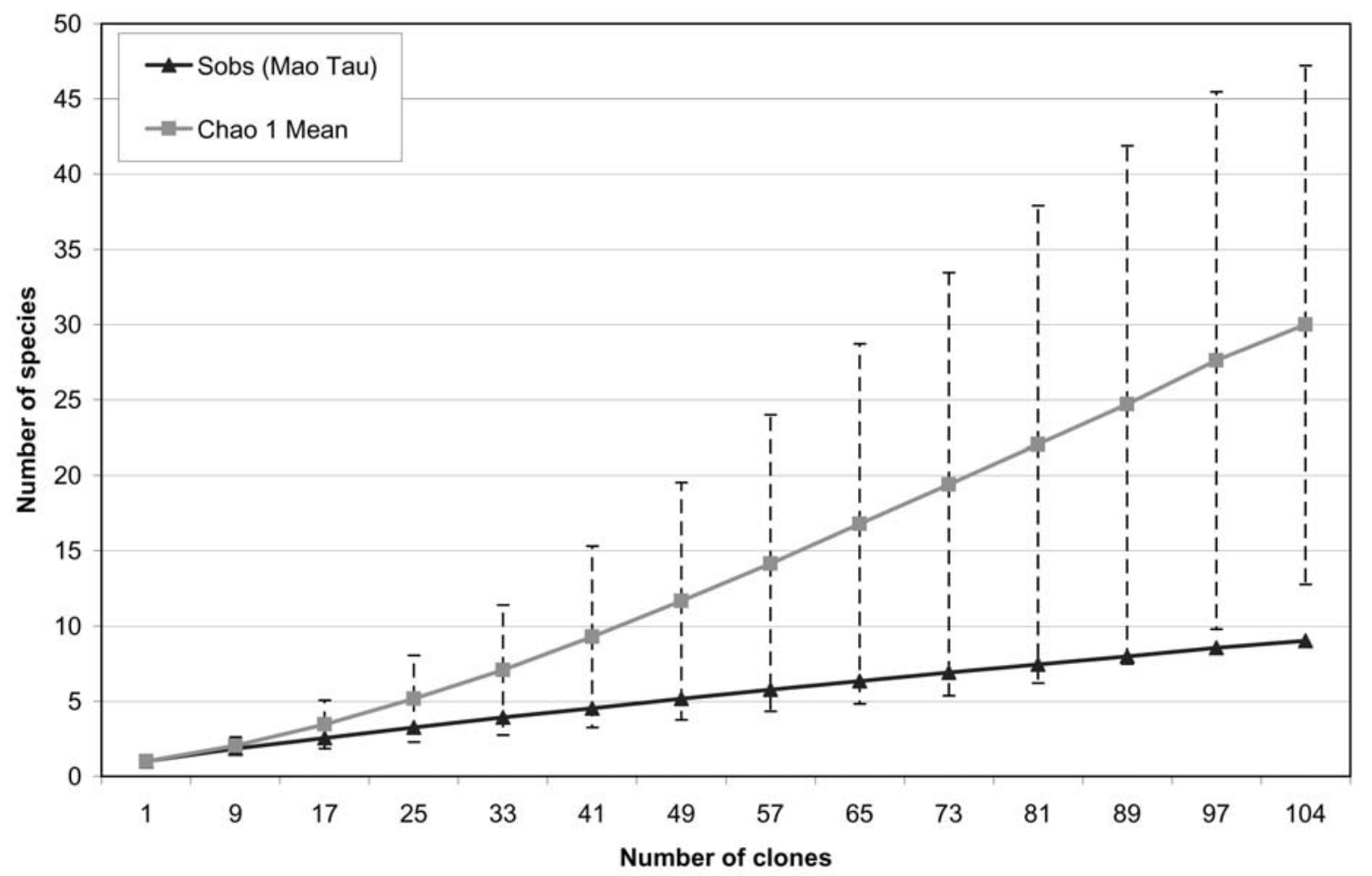

Figure 2.6. Species accumulation analysis of the 16S rDNA clone library from the Bogalusa RIFA colony. The rarefaction curve plotted the number of observed species (Sobs) as a function of the number of clones, computed with EstimateS. The Chaol estimator for species richness (after 1,000 randomizations) was plotted with its 95\% confidence interval. The Chaol estimator curve never reached a plateau and continued to slope up after 104 samples, which indicated that further sampling will result in a greater difference in estimated species richness (Hughes et al., 2001). 


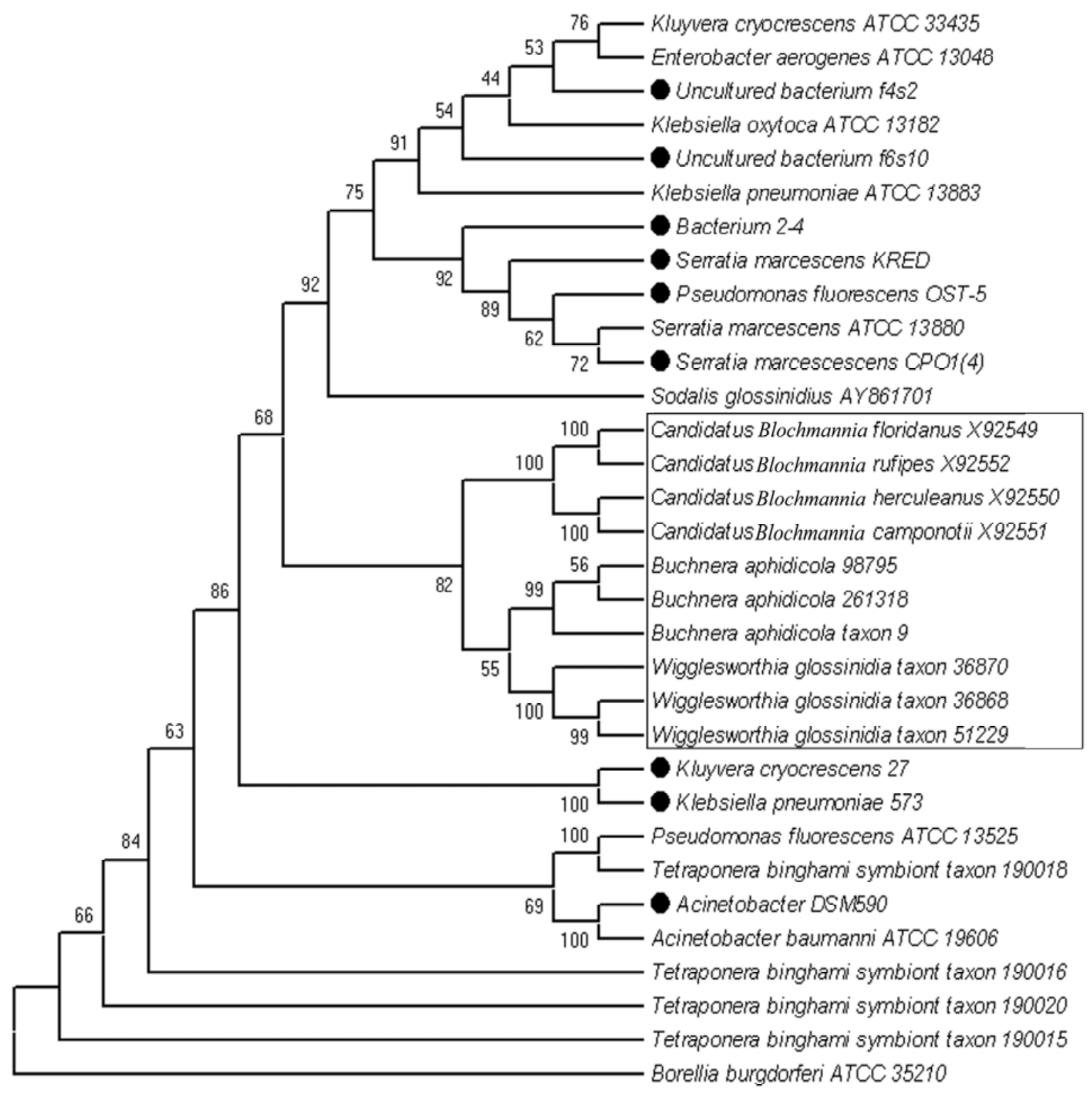

Figure 2.7. Phylogenetic affiliations of the bacteria found in the Bogalusa colony. Type strains associated with the identified bacteria along with symbionts found in carpenter ants, tree ants, aphids, and tsetse flies are included in the tree. Borrelia burgdorferi is included in the tree as the outgroup. Only the topology of the tree and bootstrap values are shown. Estimated sequence divergences were not included. The black circles represent species that were actually found in this study. Species found in carpenter ants, aphids, and tsetse flies are boxed in to illustrate that they form a strongly supported cluster out of all the other species. 
Since the inventories where found to differ based on fire ant colony location, colonies from different parts of the state or nation may have different inventories as well.

As with any chosen method of research, our methods were not perfect. Utilized PCR primers are considered universal for bacteria; however, they may be biaed to amplify certain DNA sequences better than others (Derakshani et al., 2001). One way around this concern would be to try other universal primers (DG74, RW01, RDR080, PL06) on the same sample and compare the results. Bacteria species that were missed by the 27F/1492R primer set may be detected by the other primer sets. Like PCR, the cloning reaction may also be biased and select for clones that could grow in the media. Some amplified 16S rDNA may be cloned into E. coli that somehow hinders the growth of the E. coli, making them unavailable for further analysis (Forns et al., 1997). Only those bacteria that are unhindered would grow and be selected. We are unsure if our cloning reactions experienced plasmid interference in clone growth. Based on our results and how different the inventories are between colonies, we believe that little or no interference occurred.

Predominant isolates from the Baton Rouge colony (uncultured bacterium clone p-2009-s959-5, uncultured bacterium clone LB1B7, uncultured bacterium clone 1013-1CG30) were first described from the gastrointestinal tract of pigs (Leser et al., 2002), ferromanganese deposits in Lechuguilla and Spider Caves in New Mexico (Northup et al., 2003), and transect samples in uranium contaminated aquifers (Gihring, T.M., Fredrickson, J.K., McKinley, J.P., Wilson, T.C., Long, P.E., Subsurface microbial communities and geochemistry within a vertical transect of a uranium-contaminated aquifer, unpublished, GenBank 2004), respectively. The most numerous isolate from Rosepine was Providencia stuartii. This bacterium occurs naturally in the intestinal tracts 
of humans, penguins, and stable flies (Bergey, 1984). Following Providencia stuartii in rank abundance was uncultured bacteria clone $\mathrm{f} 4 \mathrm{~s} 2$ (GenBank). This bacterium was first sequenced from gastrointestinal samples of ant lions (Dunn and Stabb, 2005). According to its 16S rRNA gene sequence, it is closely related to Klebsiella oxytoca, common in the intestines of humans and animals. Uncultured bacteria clone $\mathrm{f} 4 \mathrm{~s} 2$ was the most dominant bacteria from the Bogalusa colony. It made up $90 \%$ of the identified gut microbe community. The Bogalusa colony also had two bacteria species, Kluyvera cryocrescens and Serratia marcescens, that were cultured by Li et al. (2005) from RIFA found in Texas. However, these two bacteria species were singletons in the Bogalusa colony. The aforementioned may have been picked up by chance from the environment and are not native residents of the fire ant gut. All of the other identified bacteria were not found by Li et al. (2005) or Peloquin and Greenberg (2004) who both used culture-dependent methods.

One of the criteria I used to determine if a bacteria species was an obligate endosymbiont of RIFA larvae was whether or not it was present among all three colonies. One species was found to be present in all of the colonies; this was Klebsiella pneumoniae (Table 2.5). It was a singleton in two colonies and made up 7\% of the third colony. Klebsiella pneumoniae is ubiquitous in the intestinal tracts, mouths, and skin of animals (Bergey, 1984). The bacterium was not numerically dominating in all three colonies, arguing against an obligate endosymbiotic characteristic. In termites a Bacteroidales species made up $70 \%$ of the termite gut flora. This bacterium formed clusters with sequences cloned from termite guts in other studies, which suggests the existence of termite-specific bacterial lineages (Shinzato et al., 2005). In aphids, there are 5-24 x $10^{6}$ endosymbiotic bacteria $\mathrm{mg}^{-1}$ aphid fresh weight (Wilkinson, 1998). Greater 
Table 2.5. Species of bacteria common to at least two RIFA colonies studied. The name of the bacteria species and their proportion in the microbial community specific to a colony are shown.

\begin{tabular}{ccc}
\hline Baton Rouge Colony & Rosepine Colony & Bogalusa Colony \\
Klebsiella pneumoniae $(7 \%)$ & Klebsiella pneumoniae $(1 \%)$ & Klebsiella pneumoniae $(1 \%)$ \\
Klebsiella oxytoca $(3 \%)$ & Klebsiella oxytoca $(2 \%)$ & \\
Proteobacterium Core-2 (2\%) & Proteobacterium Core-2 (2\%) \\
Enterobacter cloacae $(1 \%)$ & Enterobacter cloacae $(3 \%)$ & \\
& Uncultured bacterium f4s $2(9 \%)$ & Uncultured bacterium f4s $2(90 \%)$ \\
\hline
\end{tabular}


than $75 \%$ of the bacteria are in embryos. Such lineages and numbers of obligate endosymbionts do not appear to be present in RIFA.

Culture-independent techniques provided a comprehensive look at the bacteria communities in each colony. Species diversity indices and estimators yielded significantly different values for all three colonies. The Chaol estimator (with 95\% confidence intervals) provided a wide range of values for detected richness estimations. These ranges encompassed the other rare-species estimator (Jack1), abundance estimator (ACE), and incidence estimator (ICE). None of the estimators indicated that $>85 \%$ of the bacteria community of a colony was identified. The colony with the highest bacteria diversity and evenness according to the Shannon and Simpson indices was from Baton Rouge. Next in terms of diversity and evenness was the colony from Rosepine. The Bogalusa colony had the lowest species diversity and the most uneven species distribution, as indicated by the Shannon and Simpson indices. Such variation in diversity and evenness is not expected if the colonies had similar bacteria community compositions.

Phylogenetic trees in my study showed that endosymbionts from carpenter ants, tsetse flies, and aphids may share a common endosymbiotic lineage as shown in figures 2.3, 2.5, and 2.7. Endosymbionts of tree ants formed tight clusters with themselves and with a few environmental bacteria species. Bacteria identified in RIFA did not form clusters with these groups. Bacteria identified in RIFA formed clusters with other closely related environmental bacteria away from the known primary symbionts in other insects such as carpenter ants, tsetse flies, and aphids (Sauer et al., 2002, Cheng and Aksoy, 1999). Based on the phylogenetic trees, there is no evidence of specialized obligate endosymbiosis between the identified bacteria and RIFA. 
The reason for the lack of obligate endosymbiosis may be due to diet. The red imported fire ant diet consists of dead animals, insects, earthworms, and invertebrates. Workers also collect honeydew and forage for sweets, proteins, and fats (Vinson and Sorenson, 1986). A diverse diet such as this suggests that the fire ants acquire all essential nutrients from their diet. Unlike termites, individuals of Tetraponera, and Camponotus, RIFA may not need specialized obligate endosymbionts to supply it with supplemental nutrients such as nitrogen and sulfur. The RIFA gut bacteria communities are contributed by substances ingested from the environment, similar to pharaoh ants.

Within the spectrum of symbiotic associations in ants the symbionts of RIFA represent transient species derived from the environment, similar to bacteria found in pharaoh ants. In contrast to Camponotus and Tetraponera, which represent the other end of the spectrum, RIFA does not harbor obligate coadapted endosymbionts in their guts. It is possible coadapted endosymbionts may exist in other parts of the larvae's body or in other stages of development. However, the fourth-instar larvae remain the stage primarily responsible for the digestion of solid food and the source of nutrients for the queen and adult workers through production of chymotrypsin-like and elastase-like proteinases (Whitworth et al., 1998). In termite and carpenter ant examples, nutrients and enzymes that facilitate food digestion are sometimes made from obligate endosymbionts. The results of our study show this to not be the case. Rather, digestive proteinases found in RIFA are more likely formed independently from glands inside the gut. In an effort to acquire more data to support this conclusion of transience, I used additional techniques and methods. The following chapters will continue to add data in support of the transient nature of the bacteria in the fire ants. 


\section{CHAPTER 3}

\section{EIGHTY TWO DAYS LATER - BOGALUSA REVISITED: EFFECT OF CAPTIVITY ON FIRE ANT MICROBIAL DIVERSITY \\ Introduction}

Red imported fire ant larvae from Louisiana did not appear to contain obligate endosymbiotic microorganisms in their guts (Chapter 2). With the three colonies having different sets of bacteria in their fourth-instar larvae, the results suggested that the bacteria communities can be changed based on what is fed to the ants. Colonies from each unique location in Louisiana were exposed to unique environmental conditions. Ants from Baton Rouge were collected from a dirt parking lot; ants from Rosepine were collected from an empty pasture; ants from Bogalusa were collected from a pasture occupied by cows. Based on my findings (Chapter 2) the food the ants consume at each location is presumably different, so the fact that differences existed at each location is not surprising. From the previous study, once a colony was brought into the lab the fourthinstar larvae were immediately removed to analyze the bacteria in their guts. The colony itself was kept alive for other experiments. After a period of about two and a half months, the RIFA colonies would have underwent several generations of workers. Larval stages only last 6-12 days (Vinson and Sorensen, 1986), which ensures that several generations, have been produced in the colony since the initial move to captivity. I hypothesized, based on previous results, that bacteria found in ants in captivity would be different from the time when they were first brought in to the lab.

\section{Materials and Methods}

Of the three colonies used in Chapter 2, the colony from Bogalusa was the only one that still had queens and brood after months in captivity. As the sole-survivor of the 
three colonies initially studied, it could be accessed again for a follow-up analysis. Fire ants were reared in plastic boxes with Teflon as described in chapter two. Food and water were provided in the form of dead crickets (Fluker Farms, Port Allen, LA), tap water, and $50 \%$ sugar water. My rearing method was based on the protocol described by Banks et al. (1981). All food sources and water were replenished as needed.

All the available fourth-instar larvae (32) were taken out of the colony followed by aseptic isolation of their guts. Larval guts were then homogenized in a common reaction tube and bacteria DNA was extracted with the Qiagen DNeasy Tissue kit. The DNA was used as templates to perform 16S rDNA PCR. Amplification was done with the universal 16S rRNA primers 27F and 1492R (Lane, 1991). PCR products were purified and a clone library was established utilizing E. coli. Clones with the 16S rDNA insert were selected and M13 PCR was performed to amplify the DNA of interest. The Li-Cor 4300 DNA Analyzer used to sequence the colonies described in Chapter two was malfunctioning at this point in the experiment so amplified ribosomal DNA restriction analysis (ARDRA) was used in conjunction with a commercial sequencing service. Though ARDRA typically underestimates the number of unique bacteria in a sample, I still found more bacteria species in this experiment than I did with the field-fresh colony. Given the working conditions, I assumed that sequencing and ARDRA would yield comparable results. Detailed description of methods used for DNA extraction, PCR, cloning, phylogenetic tree construction, and species accumulation curve construction can be found in Chapter two.

ARDRA required the $16 \mathrm{~S}$ rDNA fragments to be restricted to create unique banding patterns. Purified 16S rDNA products were digested with HaeIII and RsaI restriction enzymes to generate banding patterns for each clone. Each digestion reaction 
contained $15 \mu \mathrm{L}$ of PCR product, $2(\mu \mathrm{L})$ of 10X NEBuffer 1 (New England Biolabs, Beverly, Massachusetts), $3 \mu \mathrm{L}$ PCR quality water, $0.25 \mu \mathrm{L}$ of RsaI (2.5 units), and 0.25 $\mu \mathrm{L}$ of HaeIII (2.5 units). Each reaction was incubated in an MJ Research PTC-200 Peltier Thermal Cycler. The incubation program consisted of $2 \mathrm{~h}$ at $37^{\circ} \mathrm{C}, 20 \mathrm{~min}$ at $80^{\circ} \mathrm{C}$, and finally a storage temperature of $4^{\circ} \mathrm{C}$. Incubated products were then loaded onto a $1 \%$ agarose gel and banding patterns were examined visually. Clones with unique patterns were isolated and sequenced at the University of California, Riverside's Core Instrumentation Facility. Once the sequences were returned, Vector NTI version 7 was used to form contiguous sequences. Sequences were then compared to entries in GenBank through BLAST. Once clone identities were established, a phylogenetic tree and species accumulation curves were created using MEGA 3.1 (Kumar et al., 2004) and EstimateS (Colwell, 1994-2001), respectively.

\section{Results}

I detected 12 bacteria species identified from 130 clones in the lab-reared Bogalusa colony. Captivity increased this colony's bacterial diversity (Shannon index: $\mathrm{H}$ $=1.08,1$-Simpson index: $1-\mathrm{D}=0.51$. These values indicated that two individuals picked at random from this community will be different species in $51 \%$ of all cases). When the colony was fresh from the field, it had a 1 -Shannon index $=0.50$ and a Simpson index $=$ 0.19 . The majority of bacteria (72\%) were from the phylum Proteobacteria and family Enterobacteriaceae. Phylum Firmicutes and family Streptococcaceae made up the remaining inventory (28\%). Dominant species were Enterobacter cloacae and Lactococcus garvieae. Table 3.1 lists all the identified bacteria from this experiment.

The species accumulation Chaol curve (Figure 3.1) leveled off at sample 111, which suggested that increased sampling should not reveal more bacteria species. Chao1 
Table 3.1. NCBI BLAST results for the 16S rRNA gene from 130 clones from the labreared Bogalusa colony. The name, accession numbers, closest matches in GenBank, and the number of clones identified to the species (category) are displayed.

\begin{tabular}{llll}
\hline Closest match in GenBank & Accession\# & $\begin{array}{l}\text { \% identity to } \\
\text { closest match }\end{array}$ & $\begin{array}{l}\text { Number } \\
\text { of } \\
\text { clones }\end{array}$ \\
\hline Enterobacter cloacae & AJ251469 & $>99 \%$ & 86 \\
Lactococcus garvieae isolate 36 & AY946285 & $>99 \%$ & 29 \\
Citrobacter freundii strain BRN1 & DQ517285 & $>99 \%$ & 3 \\
Enterococcus faecalis ATCC 19433 & DQ411814 & $>99 \%$ & 2 \\
Enterobacter cloacae subspecies dissolvens & DQ988253 & $>99 \%$ & 2 \\
Uncultured bacterium P2D1-740 & EF510442 & $>99 \%$ & 2 \\
Lactococcus garvieae NRIC 0612 & AB267905 & $>99 \%$ & 1 \\
Enterococcus faecalis TUA 2495L & AB098122 & $>99 \%$ & 1 \\
Bacterium spbL1 type3-1 & DQ321639 & $>99 \%$ & 1 \\
Klebsiella sp. GR9 & DQ100465 & $>99 \%$ & 1 \\
Enterobacter aerogenes taxon 548 & AF395913 & $>99 \%$ & 1 \\
Uncultured bacterium rRNA238 & AY959011 & $>99 \%$ & 1 \\
\hline
\end{tabular}




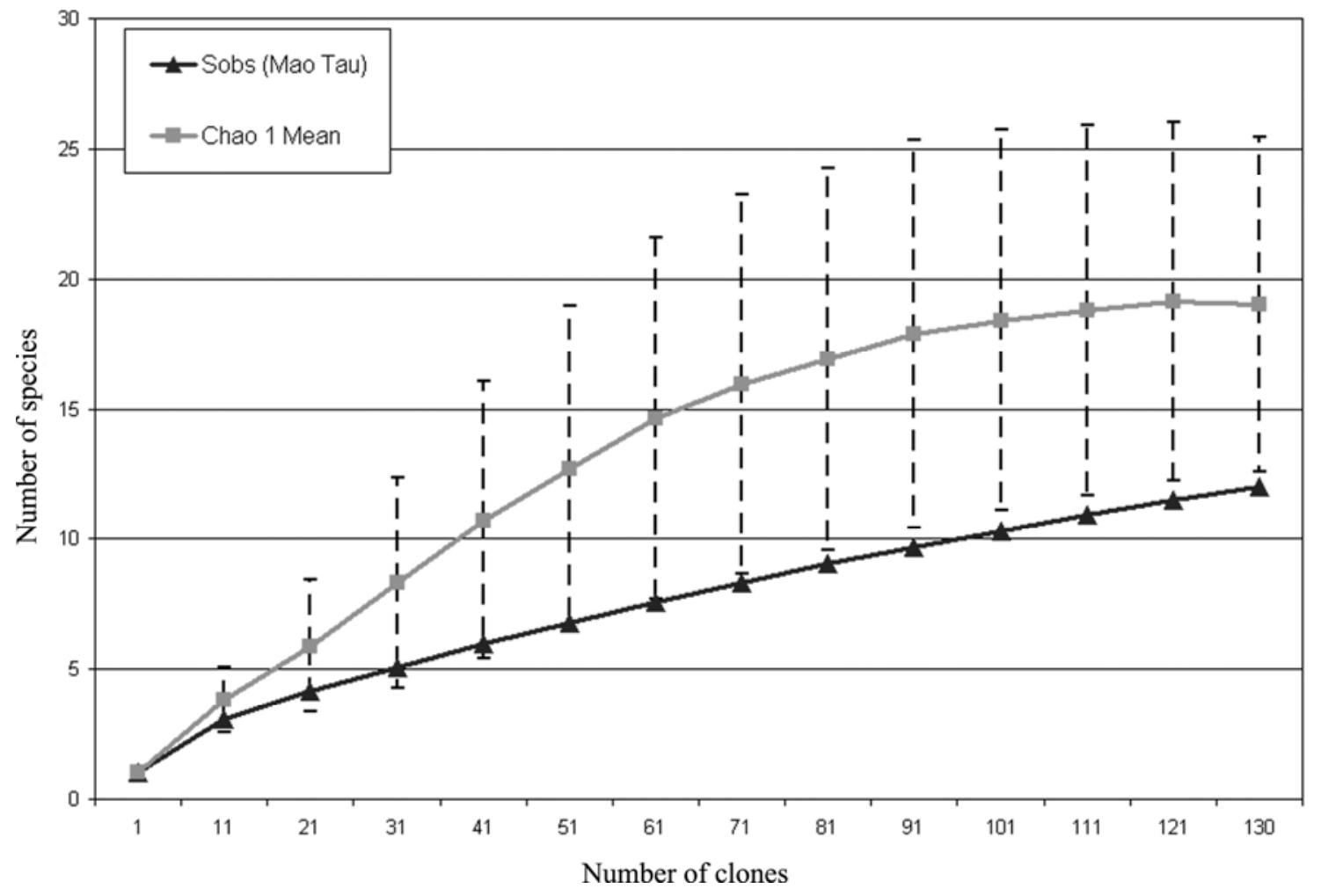

Figure 3.1. Species accumulation analysis of the $16 \mathrm{~S}$ rDNA clone library from the labreared Bogalusa RIFA colony. The rarefaction curve, plotting the number of observed species (Sobs) as a function of the number of clones, was computed with EstimateS. The Chao1 estimator for species richness (after 1,000 randomizations) was plotted with its $95 \%$ confidence interval. At the level point (111 samples) the Chao1 estimate of the number of species does not increase with the number of sampled clones. 
indicated that between $47-96 \%$ of the actual bacterial richness was identified. That percentage range was obtained by dividing the number of unique species found by the lower and upper bounds of the Chao1 estimator 95\% confidence interval. Rare-species based estimator Jack1 indicated that between $56-77 \%$ of the bacterial richness was identified. Both the ACE and ICE estimators indicated that about $47-57 \%$ of the bacterial richness was identified.

Bacteria from this colony were not closely related to the symbionts of carpenter ants, aphids, and tsetse flies, which formed a unique and well-supported branch in the phylogenetic tree (Figure 3.2). Tree ants (Tetraponera spp.) symbionts were found in neighboring clades.

\section{Discussion}

My study successfully inventoried bacteria in fourth-instar RIFA larvae guts that have been lab reared for 82 days. With the lab diet, the inventory of bacteria found in the ant guts completely differed from the one obtained when the colony was first brought in from the field. Comparisons between tables 3.1 and 3.2 indicated that there were no common species found between the studies even though I used the same colony. The bacterial inventory was strongly affected by laboratory rearing. My results suggest that bacteria associated with the laboratory diet of crickets and sugar water or the

environment may have transferred to the ants. Enterobacter cloacae and Lactococcus garvieae may have been in high abundance in the laboratory diet. We did not check for the presence of bacteria in the ant diet.

This conclusion was supported by the work of Jouvenaz et al. (1996). They contaminated food with Serratia marcescens and fed it to fourth-instar larvae. The $S$. marcescens were isolated from all tested larval midguts. Data from Chapter two supports 


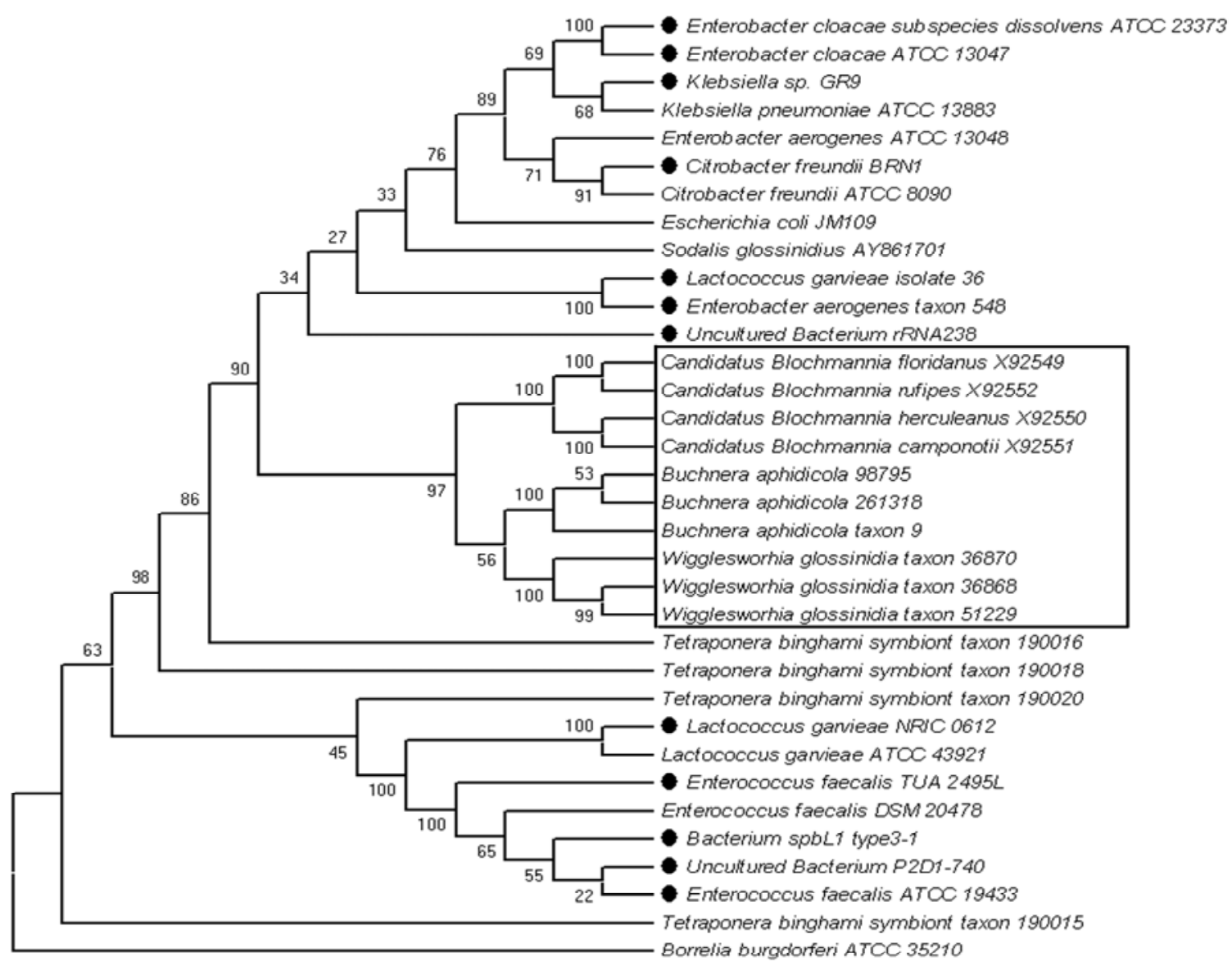

Figure 3.2. Phylogenetic affiliations of the bacteria found in the Bogalusa colony after 82 days. Type strains associated with the identified bacteria along with symbionts found in carpenter ants, tree ants, aphids, and tsetse flies are included in the tree. Borrelia burgdorferi is included in the tree as the outgroup. Only the topology of the tree and bootstrap values are shown. Estimated sequence divergences were not included. The black circles represent species that were actually found in this study. The species found in carpenter ants, aphids, and tsetse flies are boxed in to illustrate that they form a strongly supported cluster out of all the other species. 
Table 3.2. NCBI BLAST results for the 16S rRNA gene from 104 clones from the fieldfresh colony collected from Bogalusa. The name, accession numbers, closest matches in GenBank, and the number of clones identified to the species (category) are displayed. (Data from chapter two)

\begin{tabular}{lllc}
\hline Closest match in GenBank & Accession\# & $\begin{array}{l}\text { \% identity to } \\
\text { closest match }\end{array}$ & $\begin{array}{l}\text { Number } \\
\text { of } \\
\text { clones }\end{array}$ \\
\hline Uncultured bacterium f4s2 & DQ068792 & $>99 \%$ & 94 \\
Bacterium 2-4 & $\begin{array}{l}\text { DQ163943 } \\
\text { Kluyvera cryocrescens 27 }\end{array}$ & $>99 \%$ & 3 \\
Pseudomonas fluorescens OST-5 & DQ946284 & $>99 \%$ & 1 \\
Acinetobacter sp. DSM 590 & AS16SRRNB & $>99 \%$ & 1 \\
Serratia marcescens KRED & AB061685 & $>99 \%$ & 1 \\
Klebsiella pneumoniae 573 & AY830396 & $>99 \%$ & 1 \\
Serratia marcescens CPO1(4) & SMA296308 & $>99 \%$ & 1 \\
Uncultured bacterium f6s10 & DQ068816 & $>99 \%$ & 1 \\
\hline
\end{tabular}


the conclusion that the bacteria in the guts of fourth-instar larvae are determined by their diet. Our evidence along with Jouvenaz et al. (1996) supports the idea the fire ants pick up bacteria from their environment.

Enterobacter cloacae are bacteria commonly found in human and animal feces and are not an enteric pathogen. However, E. cloacae is an opportunistic pathogen capable of infecting the urinary tract, sputum, and respiratory tract of animals. As a fecal bacterium it is very common in water, sewage, and soil (Bergey, 1984). Enterobacter cloacae's presence in the inventory was not surprising since crickets could have easily picked them up as they foraged for food or simply by interacting with the environment. Attempts were made to establish how the lab reared crickets were produced by the supplier but the company never replied. Other identified bacteria in the inventory fell into the same niche as E. cloacae. These include Enterococcus faecalis, Klebsiella spp., uncultured bacterium rRNA238, and uncultured bacterium P2D1-740. Both uncultured bacteria identified here had similar DNA sequences with fecal bacteria.

Lactococcus garvieae was the second most abundant bacteria in the inventory. Identified as a major pathogen of fish (Eldar et al., 1999) and a causative agent for bovine mastitis (Bergey, 1984), this bacterium may be present in soil and contaminated water. All three field-fresh colonies I examined did not have a single clone representing $L$. garvieae. The bacterium's presence clearly came from the laboratory food or laboratory environment. Preliminary studies done with whole larvae that have been in the lab for about two weeks also had large numbers of L. garvieae in their systems (see Appendix A). My study was not the first one to identify L. garvieae in RIFA. Peloquin and Greenberg (2004) and Li et al. (2005) found this bacterium in their culture-dependent 
methods. Studies done Li et al. (2005) had one thing in common with my lab-reared colony. Both of the colonies did not appear to be fresh from the field.

From this study I conclude that RIFA does not harbor obligate symbionts. My study provides more evidence that most, if not all of their internal bacteria were derived from the environment. If this were not the case then bacteria inventories should be similar despite rearing the ants in the lab for 82 days. Diversity indices and species accumulation curves should also be similar. To further investigate this finding I continued with an experiment meant to eradicate all bacteria in RIFA and to observe mortality. An obligate symbiont may have been hidden from PCR amplification due to the abundance of other bacteria. Absence of an obligate symbiont should result in increased ant mortality or affect the maturation process.

Data from this experiment raised certain questions and possible applications. Bacteria inventories were changed in the lab, but how fast is the turn over? We know the rate will be less than or equal to 82 days. Transient bacteria can be taken up by the ants; can they also be transmitted to the environment and each other? From a public health perspective RIFA may be able to spread pathogens mechanically like roaches and pharaoh ants in nursing homes and hospitals in addition to providing painful stings. Evidence for coadapted endosymbionts in RIFA was lacking, but further research into the transient nature of bacteria associated with these ants may prove fruitful. Li et al. (2005) and Jouvenaz et al. (1996) were able to recover and culture live samples from ant guts. Their data suggests that ingested bacteria are viable. Red imported fire ants are omnivorous and seem to have no discrimination when it comes to eating contaminated or uncontaminated food. Transgenic bacteria derived from natural environments may be engineered and introduced to the ant for control. In the field-fresh Bogalusa colony I 
found a strain of Serratia marcescens in the fourth-instar larvae. Jouvenaz et al. (1996) fed Serratia marcescens to RIFA and was able to recover them in larvae. If Serratia marcescens is to be utilized in biological control, the bacterium may have to be modified to affect adult workers since they were not recovered outside of larvae. 


\section{CHAPTER 4}

\section{EFFECT OF ANTIBIOTICS ON RED IMPORTED FIRE ANT MORTALITY}

\section{Introduction}

My work with three red imported fire ant colonies from Louisiana did not yield results that would support the idea of presence of coadapted bacteria in fourth instar larvae. Bacteria in the larval guts were identified by molecular techniques. Molecular techniques and their life histories indicated that they were environmentally derived. Restricted diets in captivity may have caused the ants to take on a completely new bacterial inventory as shown in chapter three. As powerful as molecular techniques are, they do have limitations in that abundant DNA templates can mask the presence of less abundant ones during amplification. If a bacterium was not represented by a clone in the library, it does not necessarily mean that it is not present in the gut microbial community. This leaves the possibility that the presence of symbionts may be masked by the environmentally-derived bacteria.

Sauer et al. (2002) found that the "Candidatus Blochmannia floridanus endosymbiont" in the ant of the genus Camponotus floridanus is most important during embryogenesis and larval development. Elimination of these endosymbionts from the oocytes had a negative effect on embryogenesis and larval development. This is reflected in reduced brood and an increase in mortality of adult ants. Ants in the tribe Cephalotini have specialized structures in their digestive tract that harbor bacteria (Caetano, 1989). These bacteria are facultative anaerobic bacteria with digestive functions (Yurman and Dominiquez-Bello, 1993). Like the carpenter ants, these ants have bacteriocytes with obligate endosymbionts. Jaffe (2001) fed antibiotics to Cephalotes pusillus and found an 
increase in mortality. The researchers concluded that some of the bacteria in the digestive tract of C. pusillus are essential to the ant, probably forming a symbiotic relationship with their host. Elimination of such bacteria caused an increase in mortality. Similarly, if RIFA are treated with antibiotics and mortality is increased, then a similar set of obligate endosymbionts maybe in RIFA. If mortality is no different from controls then my results will be more evidence rejecting the idea of obligate endosymbionts in RIFA.

\section{Materials and Methods}

The ants used were from an established laboratory colony field collected on February 23, 2005 (469 days). Multiple queens and a large number of brood were available in the colony, which indicated that it was a strong and thriving colony. Larvae were numerous enough for the three treatments and controls, each with ten replicates.

Three treatment sets represent the three antibiotics tested. Each replicate had colony fragments of $\sim 50-100$ workers counted later, and five fourth-instar larvae and about five larvae with an approximate age of first to third instars. Control colony fragments consisted of one set with ten boxes (replicates) and were setup similar to treatment boxes. Each treated colony fragment was given water, antibiotic suspended in $50 \%$ sugar water, and fresh crickets. All food and water resources were replenished every day except for crickets. Crickets were replaced when consumed or after one week. Control colonies were not provided with antibiotic solutions but were given all of the other food and water resources.

Plastic boxes $(17 \times 8 \times 4 \mathrm{~cm})$ were coated with Teflon to prevent the ants from escaping the experimental enclosure. For treatment colony fragments, each coated box was furnished with two crushed crickets, $900 \mu 1$ of water and $900 \mu 1$ of antibiotics (in treatments only) mixed with $50 \%$ sugar water in $6 \times 50 \mathrm{~mm}$ Borosilicate culture tubes 
plugged with moist cotton. Harborage sites were provided for all colony fragments in the form of plaster of Paris nests. Each nest was constructed from a Petri dish $(3.5 \mathrm{~cm}$ in diameter) and filled half-way with plaster. A shoestring $(\sim 6 \mathrm{~cm})$ was partially embedded in the plaster to facilitate moistening of the plate. Once dry, the sides of dishes were drilled to provide entry holes for the ants.

Three antibiotics were tested in this study, these included kanamycin, tetracycline, and rifampicin. Kanamycin was used by Jaffe et al. (2001) in their experiments to clear endosymbionts in Cephalotes pusillus. Tetracycline was used by Sauer et al. (2002) in their experiments to clear endosymbionts in Camponotus floridanus. The antibiotic was found to be effective against the endosymbionts of those ants. In my experiments, antibiotics were mixed with $50 \%$ sugar water to produce a $5 \%$ antibiotic solution. Ants drank from the tubes of sugar, antibiotics, and water. There were no signs of repulsion from the fluids.

Worker mortality was counted every day until the last larvae pupated. The last larvae pupated after 28 days. Dead ants were removed from each box after they were counted. At the end of the experiment, the live ants were killed and counted to determine the total number of ants in each replicate so that mortality percentages could be obtained. SAS version 9.1 (SAS Institute Inc. 2002) was used to determine similarities and differences between control and treated RIFA colonies. PROC-GLM was used to generate the residuals and determine normality. It was also used to perform an analysis of variance. The data was found to be normal so it was not necessary to transform it for the PROC-MIXED analysis (SAS Institute 2002). Mortality of antibiotic-treated adult ants for specific days was compared to each other and the control using PROC-MIXED, 
which the Tukey-Kramer analysis. Larvae were examined every day. Once they all emerged as adults the replicate was terminated.

\section{Results}

Mortality occurred evenly throughout the experiment, and survivorship curves represented type II (Schowalter, 2000) mortality/survivorship (Figures 4.1 and 4.2). Larvae were not attacked or eaten by the adult ants. Larval remains were not found in any of the boxes. Adult mortality averages and the standard deviation intervals for the control and treatments can be seen in Table 4.1. Control replicates had a worker mortality range between 30-93\% after 28 days. Mortality values averaged 78\% when the experiment ended. Ants that were given tetracycline exhibited a mortality range between $68-98 \%$ with an average of $83 \%$ at the end of the data collection period. Ants treated with kanamycin experienced a mortality range of $25-98 \%$ with an average of $74 \%$ at the end of the experiment. While ants that received rifampicin demonstrated a mortality range of $54-92 \%$ with an average of $78 \%$ at the end of the data collection period. Analysis with SAS indicated that during the 28 days of antibiotic treatment, significant differences occurred on six days. Significant differences occurred between the control and rifampicin sets on days $8,9,10$, and 15 (Table 4.2). The control differed from tetracycline on days 17 and 18. Aside from these six instances, no significant differences were detected between the treatments and the controls. A one-way analysis of variance (PROC-GLM) between the controls and treatments found no significant differences overall in the days. Types I and III p-values were all $>0.05$. The treatments themselves were not significant different from each other on any days. Adult ant mortality was plotted against time (days) in Figure 4.1. The confidence intervals from each day overlapped each other in every treatment and control. Adult ant survivorship was plotted in Figure 4.2. 


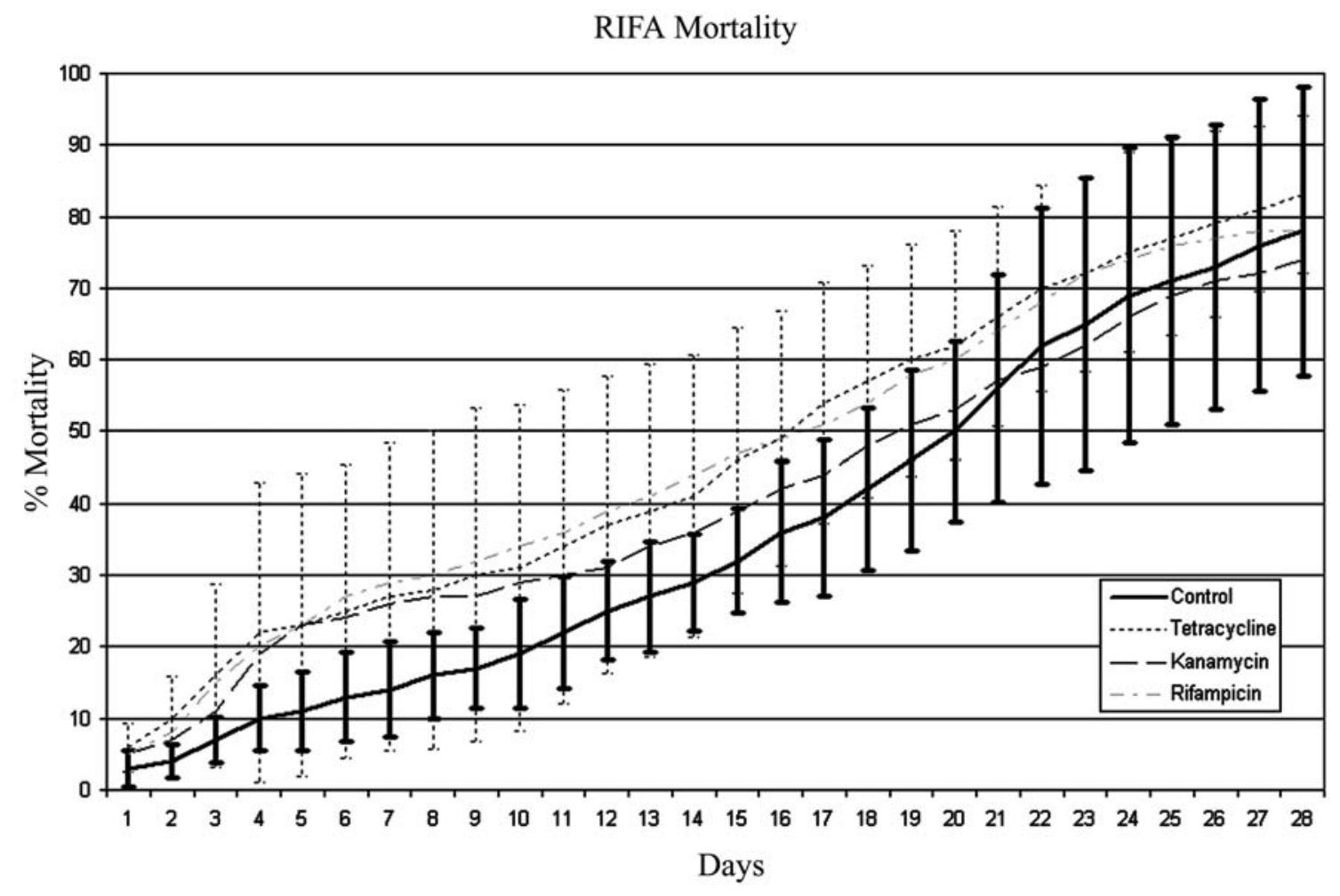

Figure 4.1. Mortality curve of untreated and treated RIFA. Means of the treatment and control for the entire duration of the experiment areshown. Standard deviations for the control and tetracycline are also shown on the graph. Standard deviations for the other treatments were not shown to preserve clarity in the graph. All of treatments and the control had standard deviations that overlapped each other indicating that their overall values were not significantly different from each other. These values can be seen in Table 4.1. 


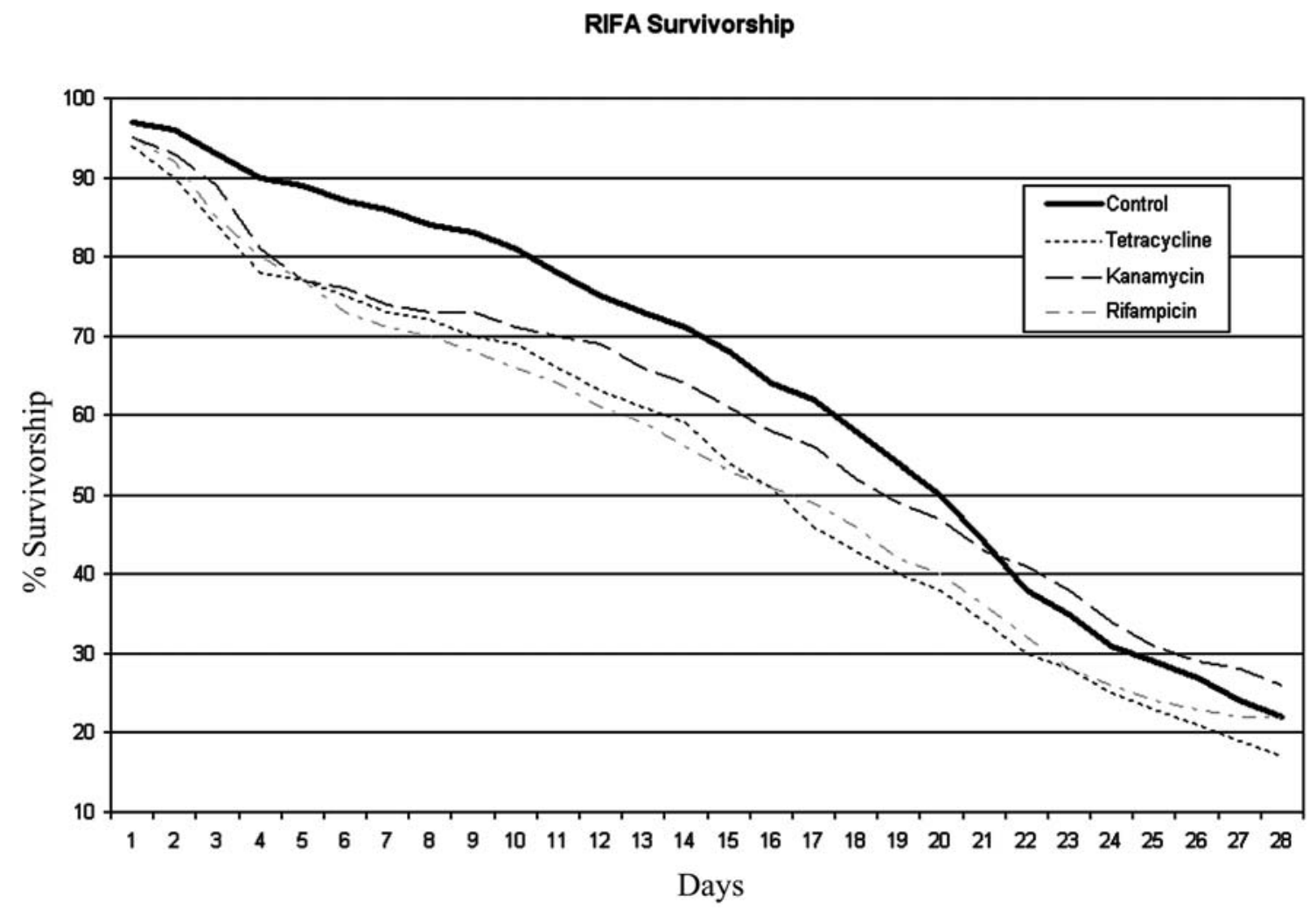

Figure 4.2. Survivorship curve of untreated and treated RIFA. The percent of live RIFA decreased at about the same rate in all of the treatments and the control. The rate is consistent with type II survivorship, indicating that mortality is occurring at a linear rate. 
Table 4.1. Red imported fire ant adult mortality averages (mean \pm standard deviation) of control and antibiotic treatments.

\begin{tabular}{|c|c|c|c|c|}
\hline Days & Control & Tetracyclin & Kanamycin & Rifampicin \\
\hline 1 & $3 \pm 2.5$ & $6 \pm 3.4$ & $5 \pm 2.9$ & $5 \pm 3.2$ \\
\hline 2 & $4 \pm 2.4$ & $10 \pm 5.9$ & $7 \pm 3.3$ & $8 \pm 5.6$ \\
\hline 3 & $7 \pm 3.1$ & $10 \pm 12.8$ & $11 \pm 5.1$ & $15 \pm 12$ \\
\hline 4 & $10 \pm 4.6$ & $22 \pm 20.9$ & $19 \pm 12.4$ & $20 \pm 14.5$ \\
\hline 5 & $11 \pm 5.4$ & $23 \pm 21.1$ & $23 \pm 13.2$ & $23 \pm 16.2$ \\
\hline 6 & $13 \pm 6.3$ & $25 \pm 20.5$ & $24 \pm 14.1$ & $27 \pm 18.7$ \\
\hline 7 & $14 \pm 6.7$ & $27 \pm 21.5$ & $26 \pm 14.6$ & $29 \pm 19$ \\
\hline 8 & $16 \pm 6$ & $28 \pm 22.2$ & $27 \pm 15.3$ & $30 \pm 20$ \\
\hline 9 & $17 \pm 5.6$ & $30 \pm 23.3$ & $27 \pm 15.3$ & $32 \pm 19.4$ \\
\hline 10 & $19 \pm 7.6$ & $31 \pm 22.7$ & $29 \pm 15.7$ & $34 \pm 19.7$ \\
\hline 11 & $22 \pm 7.8$ & $34 \pm 21.9$ & $30 \pm 16.3$ & $36 \pm 19.9$ \\
\hline 12 & $25 \pm 6.9$ & $37 \pm 20.7$ & $31 \pm 16.4$ & $39 \pm 19.3$ \\
\hline 13 & $27 \pm 7.7$ & $39 \pm 20.4$ & $34 \pm 17.2$ & $41 \pm 19$ \\
\hline 14 & $29 \pm 6.8$ & $41 \pm 19.6$ & $36 \pm 17.4$ & $44 \pm 19.2$ \\
\hline 15 & $32 \pm 7.3$ & $46 \pm 18.5$ & $39 \pm 18.6$ & $47 \pm 18.1$ \\
\hline 16 & $36 \pm 9.8$ & $49 \pm 17.8$ & $42 \pm 19.3$ & $49 \pm 18.2$ \\
\hline 17 & $38 \pm 10.9$ & $54 \pm 16.8$ & $44 \pm 19.9$ & $51 \pm 18.4$ \\
\hline 18 & $42 \pm 11.3$ & $57 \pm 16.1$ & $48 \pm 20.5$ & $54 \pm 18.3$ \\
\hline 19 & $46 \pm 12.6$ & $60 \pm 16.2$ & $51 \pm 21.4$ & $58 \pm 17.5$ \\
\hline 20 & $50 \pm 12.6$ & $62 \pm 16$ & $53 \pm 22.1$ & $60 \pm 16.1$ \\
\hline 21 & $56 \pm 15.9$ & $66 \pm 15.3$ & $57 \pm 22.1$ & $64 \pm 15.5$ \\
\hline 22 & $62 \pm 19.2$ & $72 \pm 14.4$ & $59 \pm 21.7$ & $55 \pm 15.4$ \\
\hline 23 & $65 \pm 20.4$ & $72 \pm 13.6$ & $62 \pm 23.7$ & $72 \pm 15.3$ \\
\hline 24 & $69 \pm 20.6$ & $75 \pm 14$ & $66 \pm 23.1$ & $74 \pm 14.4$ \\
\hline 25 & $71 \pm 20.1$ & $77 \pm 13.6$ & $69 \pm 22.1$ & $76 \pm 13.3$ \\
\hline 26 & $73 \pm 19.9$ & $79 \pm 13$ & $71 \pm 22$ & $77 \pm 13.3$ \\
\hline 27 & $76 \pm 20.3$ & $81 \pm 11.5$ & $72 \pm 21.2$ & $78 \pm 12.4$ \\
\hline 28 & $78 \pm 20.2$ & $83 \pm 11.0$ & $74 \pm 20.9$ & $78 \pm 12.4$ \\
\hline
\end{tabular}


Table 4.2. Significant differences detected with the Tukey-Kramer analysis between treatments.

\begin{tabular}{lll}
\hline Treatment & Day & P-value \\
\hline Control vs. Rifampicin & 8 & 0.0497 \\
Control vs. Rifampicin & 9 & 0.0401 \\
Control vs. Rifampicin & 10 & 0.0426 \\
Control vs. Rifampicin & 15 & 0.0403 \\
Control vs. Tetracycline & 17 & 0.0318 \\
Control vs. Tetracycline & 18 & 0.0473 \\
\hline
\end{tabular}


Curve patterns for all the treatments and control were linear, which indicated a regular mortality rate.

\section{Discussion}

My results from the antibiotic trials indicated no significant difference in overall mortality between control and treated colony fragments. Worker ant mortality was not visibly affected by clearing most of the bacteria in the guts of fourth-instar larvae. If coadapted mutualistic endosymbionts were present I assumed they were not resistant to all three broad-spectrum antibiotics tested. Likewise, larvae mortality was not visibly affected either. Larvae appeared healthy and were cared for by workers until they emerged into adults. No larval skins found in the boxes, indicating that cannibalism did not occur. Both larvae and workers appeared healthy during the duration of the study, which suggested that the drugs had no adverse affects on the ants. Bacteria with drug resistance genes were the only factor that may have affected our results.

When similar antibiotic experiments were done on C. pusillus, adult mortality effects were observed after $24 \mathrm{~h}$. Jaffe et al. (2001) concluded that ant mortality was probably caused by the antibiotic killing one, some, or all of the associated bacteria that are susceptible to kanamycin. Some of the bacteria in the digestive tract of C. pisillus are essential to the ant, probably forming a symbiotic relationship with the host. I not only tested kanamycin, but also tetracycline and rifampicin and found no significant differences in daily mortality in the ants except in six cases. Time periods before and after these days were no different from each other and the control, so I concluded that the differences found were outliers and the treatments and control were not significantly different from each other. Even though the presence of antibiotic-resistant bacteria may be available in the ants I studied, I assumed that the majority of the bacteria in the larvae 
were not antibiotic resistant or if they were, they would not be resistant to all three antibiotics I tested.

My data suggested that no obligate endosymbionts are in the guts of fourth-instar fire ant larvae that are important for survival. Molecular data suggested that all bacteria inventoried from larvae were environmental in origin and were consumed by the ants (Chapter 2). One colony showed $100 \%$ change in its fourth-instar larvae bacterial inventory after being fed a laboratory diet (Chapter 3). Broad spectrum antibiotic that have been shown to have an effect on C. pusillus mortality had no visible significant effect on RIFA.

Li et al. (2005) found that certain bacteria (all but an uncultured bacterium and Bacillus punilus) isolated from RIFA were resistant to antibiotics (ampicillin, chloramphenicol, doxycycline, erythromycin, gentamycin, kanamycin, kalidixic acid, neomycin, spectinomycin, streptomycin, tetracycline, zeocin). They found one bacterium that was resistant to all the drugs tested. However, most were susceptible to various drugs and only two were resistant to both kanamycin and tetracycline. The guts may not have been rendered completely bacteria free. An antibiotic cocktail may have been interesting to test on the ants in the future since it would probably render the ants closer to being bacteria-free. 


\section{CHAPTER 5}

\section{EXAMINATION OF RED IMPORTED FIRE ANT LARVAE GUTS THROUGH MICROSCOPY}

\section{Introduction}

Obligate symbionts have been found in several ant species to supplement specialized diets. Camponotus floridanus was found to have bacteriocytes containing obligate endosymbionts through the use of transmission microscopy (Sauer et al., 2002). Bacteriocytes in the midgut epithelium were full of endosymbiotic bacteria. Sauer et al. (2002) believed that the "Candidatus Blochmannia floridanus endosymbiont" in the ants of the species C. floridanus is most important during embryogenesis and larval development. Adult ants are able to live without their bacterial endosymbionts under laboratory conditions. These symbionts seem to degenerate naturally over time, as observed in older queens, suggesting that the symbiosis may be of relevance during the early stages of the ants' development (Sauer et al., 2002).

The omnivorous $C$. floridanus is also capable of feeding almost exclusively on sugary fluids due to their symbionts. Candidatus Blochmannia floridanus is able to supply nitrogen and sulfur compounds to the host through the host's metabolic machinery (Gil et al., 2003). Members of the genus Candidatus Blochmannia are closely related to other endosymbiotic bacteria of insects such as Buchnera of aphids, Wigglesworthia of tsetse flies, and, more distantly, Carsonella of psyllids. These bacteria form a clade contained within the family Enterobacteriaceae within the phylum Proteobacteria (Sauer et al., 2002).

The presence of bacteriocytes and the visibility of the bacteria provided unquestionable proof of the presence of endosymbiotic bacteria in other ants. My 
investigation focused on the fourth-instar larvae of red imported fire ants, the stage that can process solid foods (Vinson and Sorenson, 1986). After experimenting with cultureindependent methods and antibiotic mortality tests the next step was to physically examine the guts of larvae and search for bacteriocytes similar to those found in $C$. floridanus. Visual evidence is capable of either strongly supporting or questioning my molecular and antibiotic data.

\section{Materials and Methods}

The ants used were from an established laboratory colony from February 23, 2005 and the experiment began on April 16, 2007 (782 days later). Multiple queens and a large number of brood were available in the colony, which indicated that it was a strong and thriving colony. Twenty fourth-instar larvae were taken from the colony and dissected for microscopy. Personnel from the Louisiana State University's Socolofsky Microscopy Center prepared the samples and processed the larval guts for microscopy after I aseptically dissected out the guts. Multiple guts were submitted to the facility to compensate for any errors that may occur. Four gut samples were used to take the images. Light and electron microscopy were both used to examine gut structures. Entire guts of RIFA fourth-instar larvae guts were pulled out and fixed in 2.5\% glutaraldehyde and $1 \%$ paraformadehyde in $0.2 \mathrm{M}$ cacodylate buffer $(\mathrm{pH} 7.2)$ and incubated at room temperature for 2 hours. After the incubation period, the mixture was post-fixed in $1 \%$ osmium tetroxide $\left(\mathrm{OsO}_{4}\right)$ buffer for one hour, followed by a $0.1 \mathrm{M}$ cacodylate buffer wash. Upon completion of the wash, the mixture was placed in $1 \%$ uranyl acetate for block staining. The materials were dehydrated in an ethanol series and embedded in medium grade LR White Resin (London Resin Company Ltd., England). Once in place, the resin was dried in carbon dioxide using a Denton DCP-1 critical point drying 
apparatus. The blocks of resin were cut with a microtome to produce $90 \mathrm{~nm}$ thin sections. Thin sections were stained with lead citrate and then examined with a JEOL JEM 100CX transmission electron microscope (TEM). The same preparations were also used for standard light microscopy.

Two ant guts were prepared for scanning electron microscopy (SEM). They were fixed and dehydrated with the same methods described above. The guts were mounted on stubs, dissected, and coated with $25 \mathrm{~nm}$ of gold palladium using a Hummer II sputter coater, and examined on a Cambridge S-260 scanning electron microscope.

\section{Results}

Cross-sections of the foregut/midgut and hindgut did not present any bacteriocytes. Visceral muscles in the gut epithelium were clearly visible. Figure 5.1 shows the foregut/mid cross-sections and magnified areas of epithelial cells in the gut wall. Hindgut images revealed similar structures (Figure 5.2A) with the addition of circular muscles (Figure 5.2B) and bacteria (Figure 5.2C) near the gut lining.

Scanning electron micrographs of the foregut/midgut (Figure 5.3) revealed that the structure was filled with bolus and fluids fed to the larva by the adult workers. Portions of the epithelium can also be seen. Bacteriocytes were not observed in the scanning or transmission electron micrographs. Hindgut scanning micrographs showed that the hindgut had structures similar to the foregut/midgut (Figures 5.4, 5.5, and 5.6) and no evidence of bacteriocytes. Transmission electron micrographs of the hindgut did not contain bacteriocytes either (Figure 5.7).

\section{Discussion}

Carpenter ants may be capable of functioning as herbivores who subsist on a diet of sugary water. If such a life style is used the carpenter ants rely on their obligate 

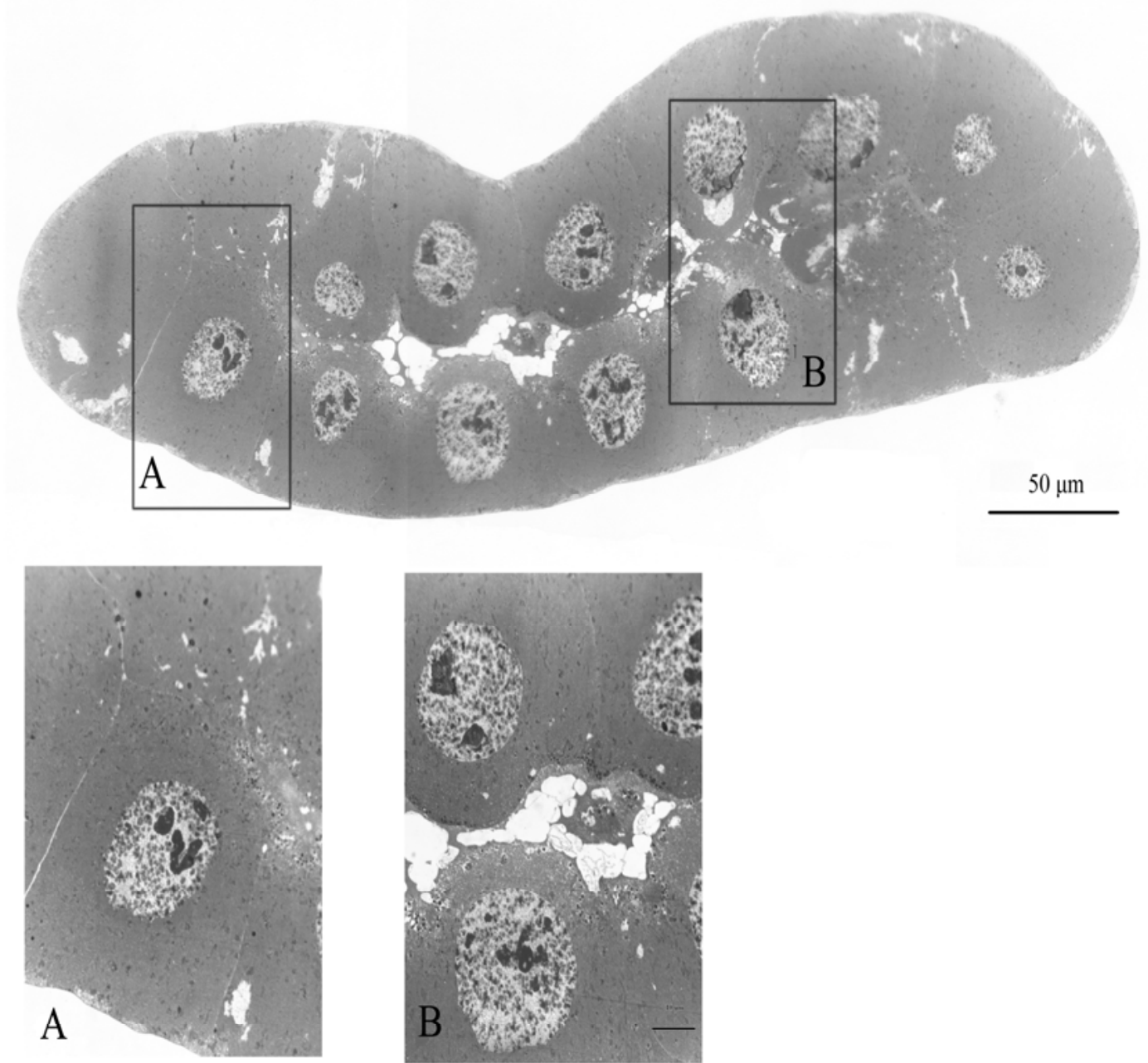

Figure 5.1. Cross-section of the foregut/midgut showing the lumen and epithelial cells. A. Epithelial cell in the gut wall. B. Epithelial cells in the gut wall and the lumen of the gut. 


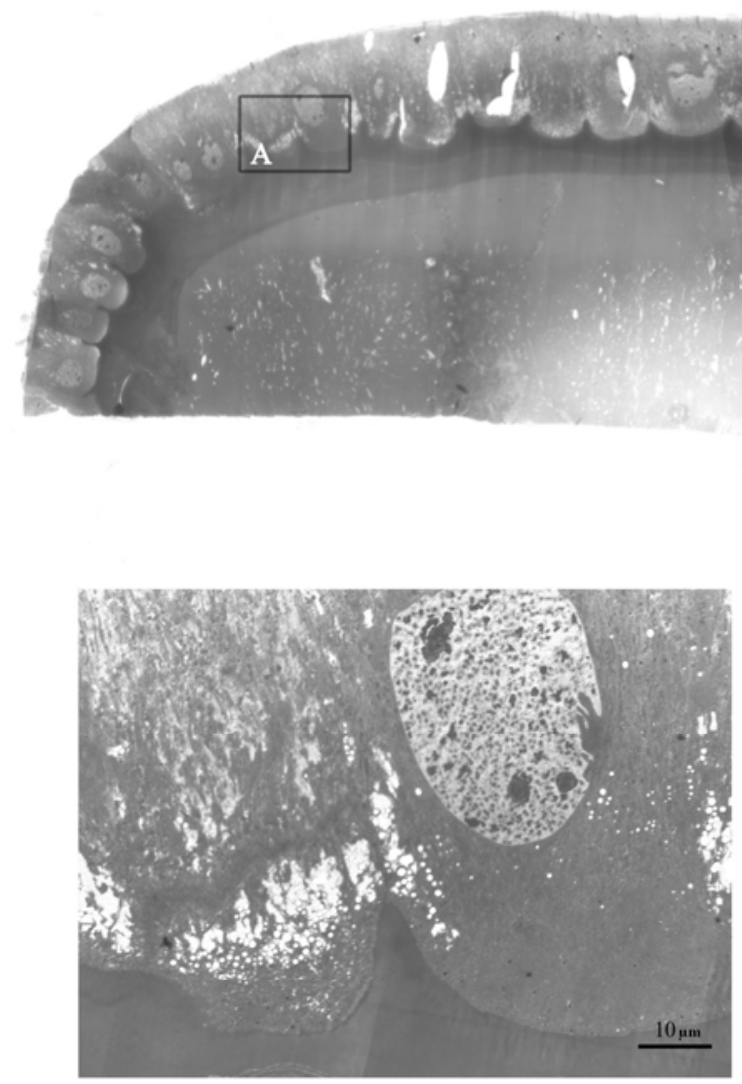

A

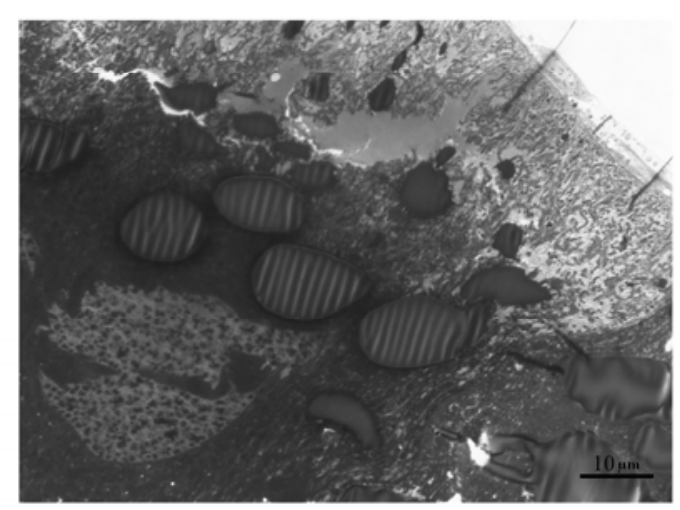

B
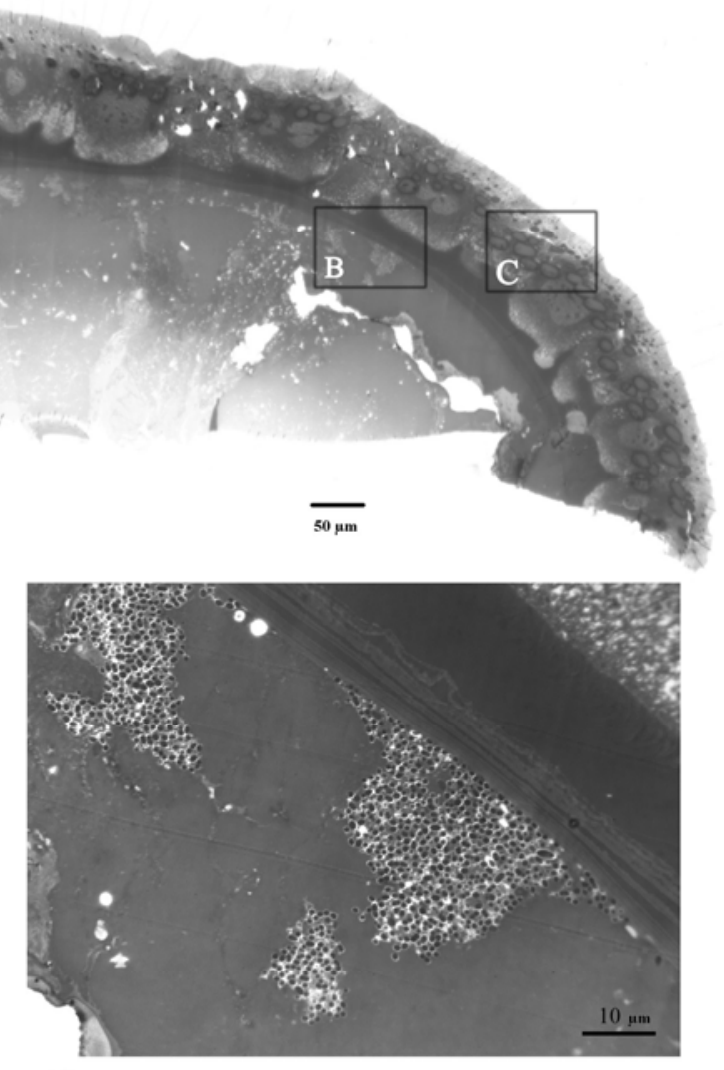

$\mathrm{C}$

Figure 5.2. Light microscopy cross-section images of a fourth-instar larva's hindgut. Letters represent magnified areas in the hindgut epithelium and lumen. A. Epithelial cell in the gut wall. B. Circular muscles in the gut wall. C. Bacteria in the lumen near the gut wall. 


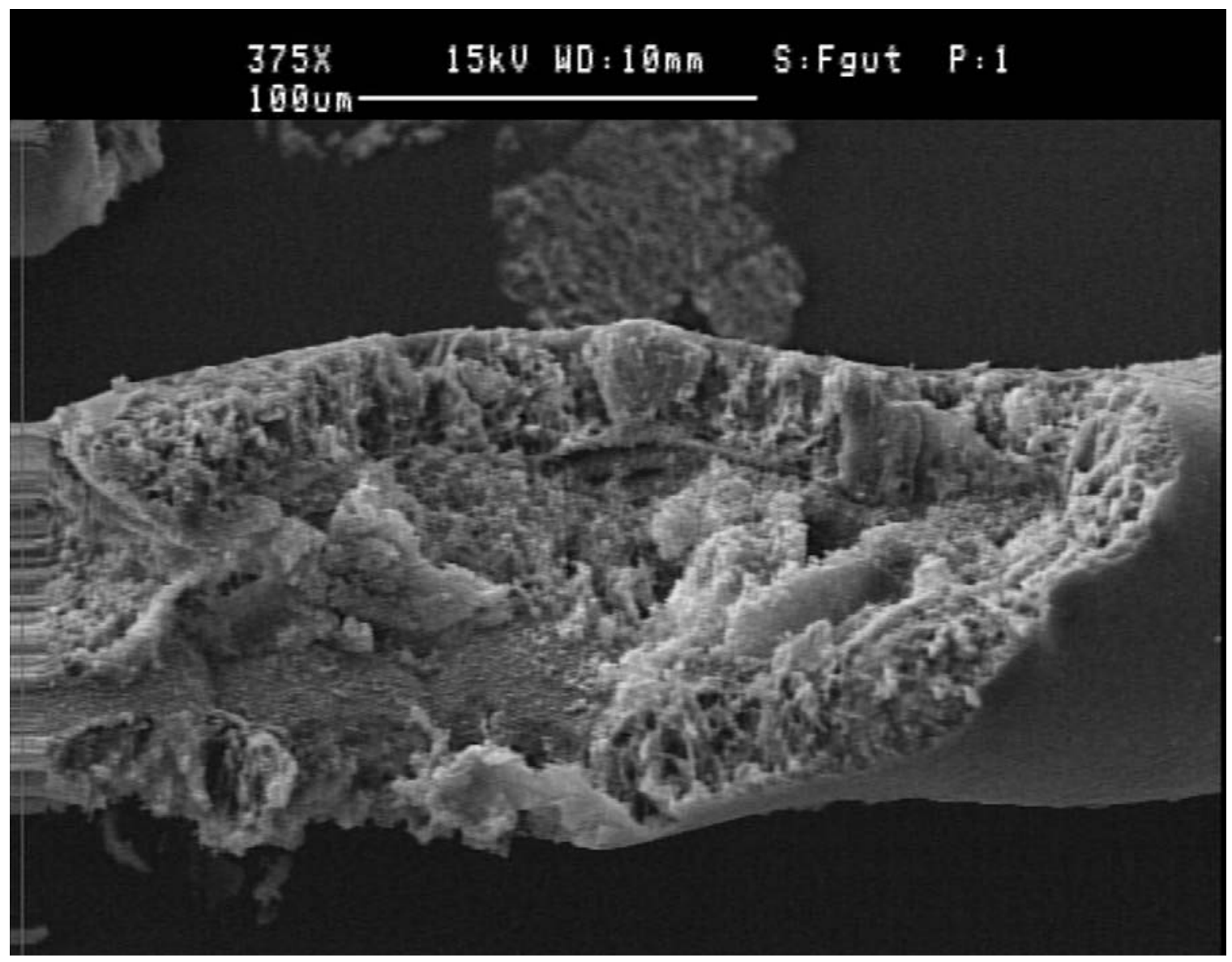

Figure 5.3. Scanning electron micrograph of the foregut/midgut of a fourth-instar larva longitudinal section. Bolus take up the bulk of space in the lumen. 


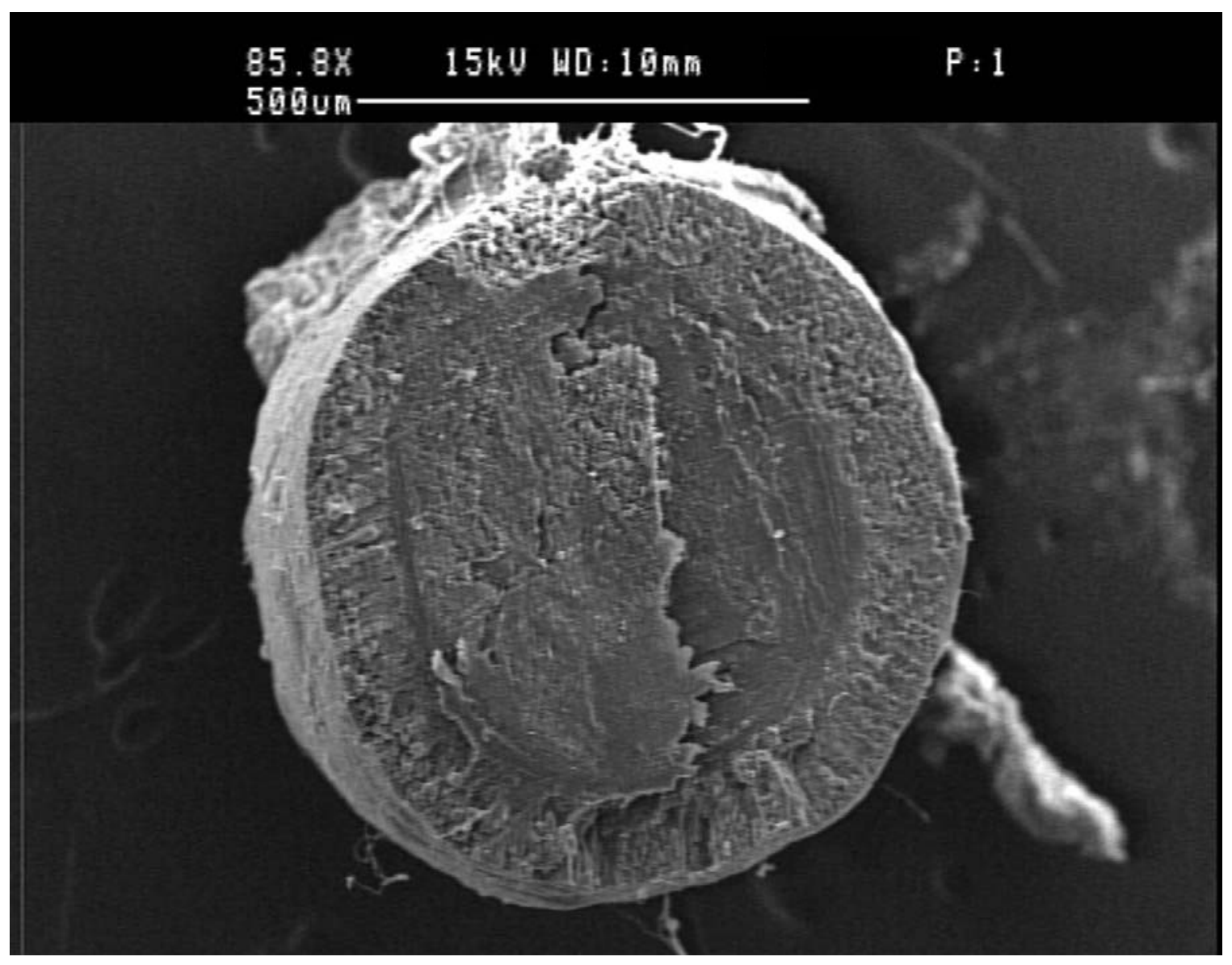

Figure 5.4. Scanning electron micrograph of the hindgut of a fourth-instar larva. The image is a cross-section of the hindgut and shows the epithelial lining with bolus inside the lumen. Fluids and food particles make up the bulk of the lumen. This material will be excreted as meconium once the larva matures. 


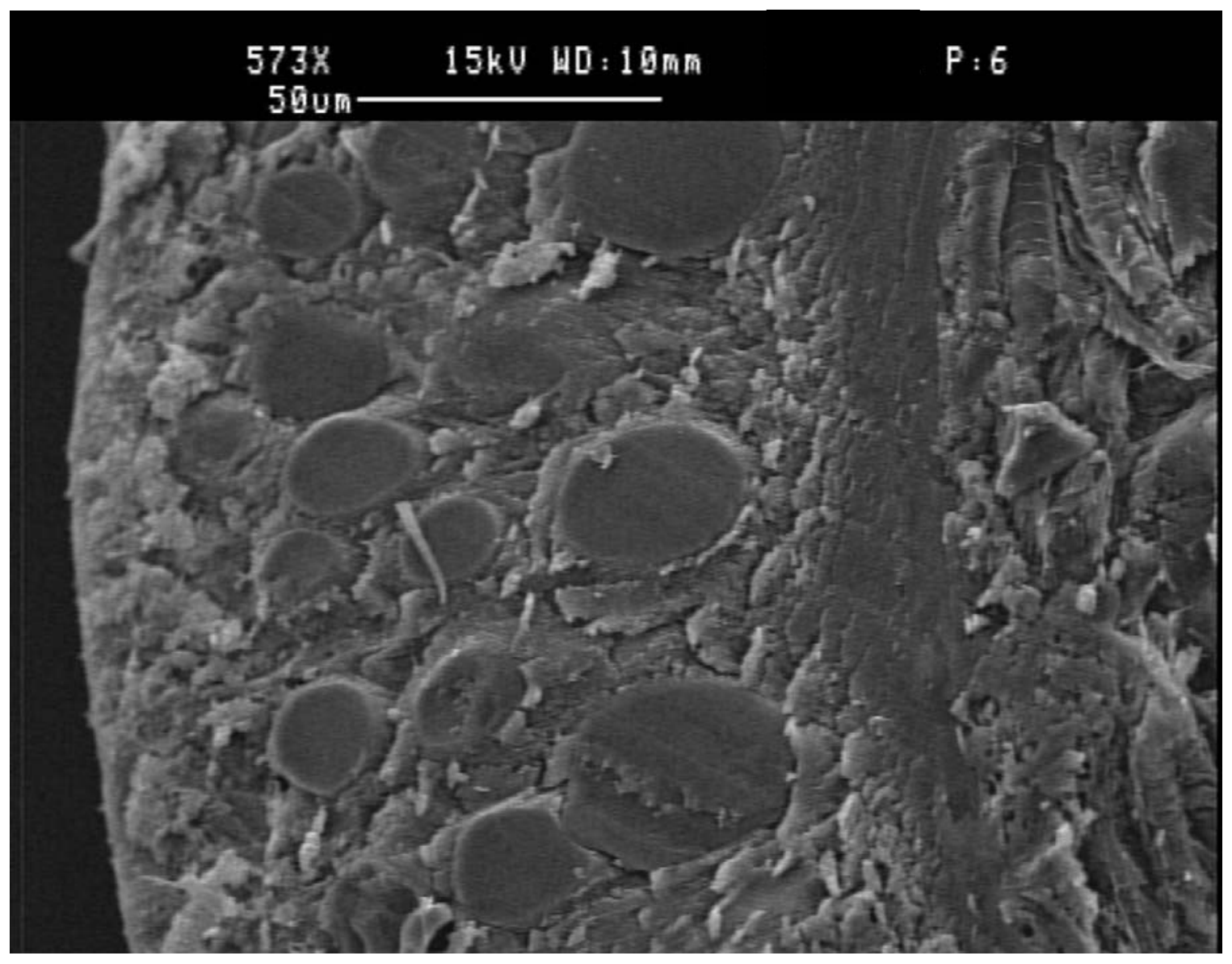

Figure 5.5. Scanning electron micrograph of the hindgut of a fourth-instar larva. The image is a cross-section of the hindgut and shows the circular muscles in the gut epithelium. 


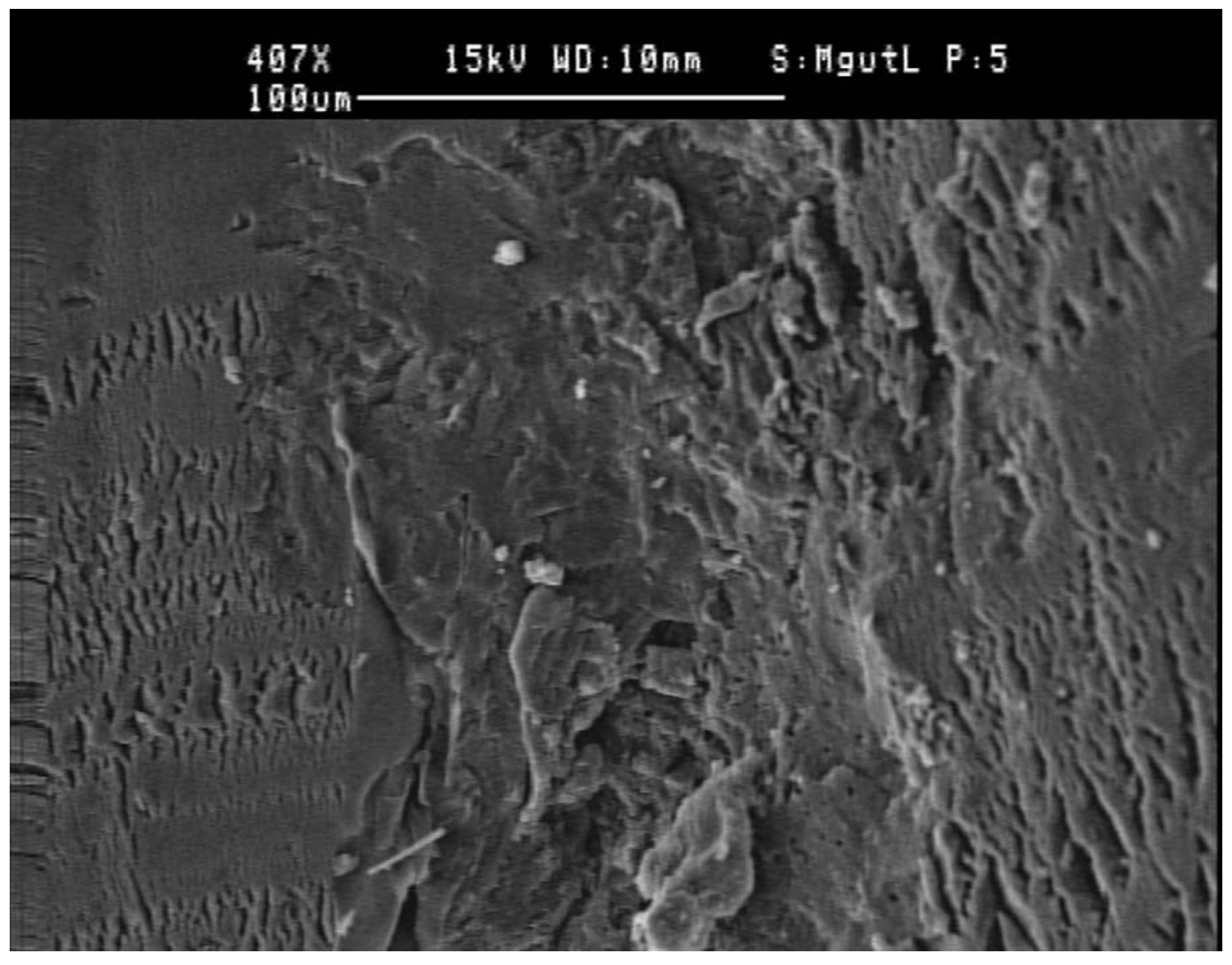

Figure 5.6. Scanning electron micrograph of the hindgut of a fourth-instar larva. The lumen of the hindgut is composed of bolus as seen in the cross-section. 

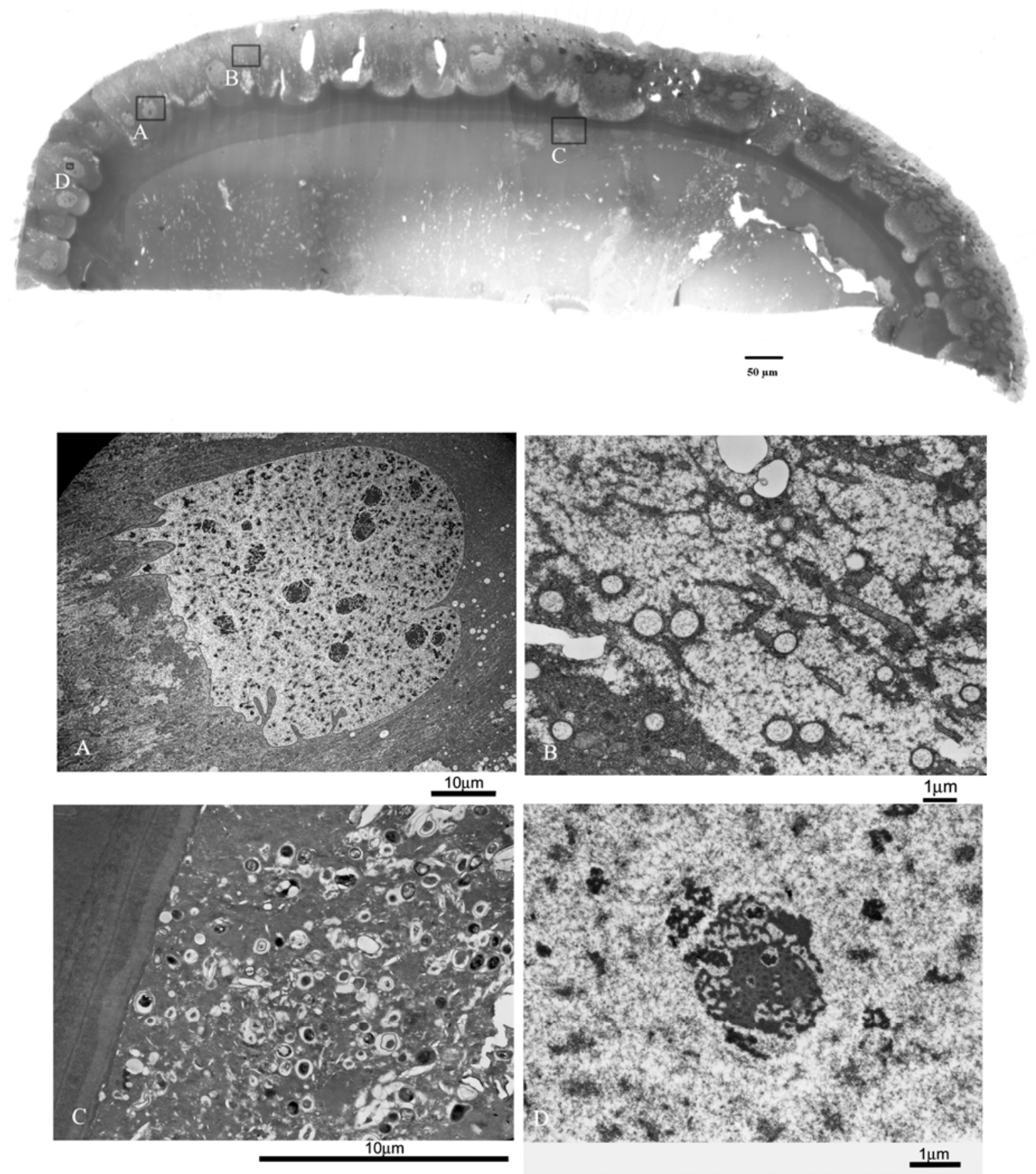

Figure 5.7. Cross-section of the hindgut of a fourth-instar larva. A light microscopy image at the top indicates the areas where transmission micrographs were taken. Images A through D are transmission electron micrographs (TEM). A. Epithelial cell in the hindgut wall. B. Unknown cells with visible mitochondria. C. Bacteria and other food particles in the lumen of the hindgut. D. Structure in the cross section of an epithelial cell. 
endosymbionts. Candidatus Blochmannia floridanus, the obligate endosymbiont is able to supply nitrogen and sulfur compounds to the host through the host's metabolic machinery (Gil et al., 2003). The endosymbiont makes it possible for the carpenter ant to feed exclusively on sugars and still be able to survive and multiply by providing nitrogen and sulfur. An alternative feeding strategy may not be present or necessary in RIFA.

RIFA diet consists of dead animals, plants, insects, earthworms, and vertebrates. Workers also collect honeydew and will forage for sweets, proteins, and fats (Vinson and Sorenson, 1986). A diverse diet such as this suggests that the fire ants acquire all their essential nutrients from their diet. RIFA may not need specialized obligate symbionts to supply it with supplemental nutrients such as nitrogen and sulfur. RIFA gut bacteria communities are contributed by substances ingested from the environment, similar to pharaoh ants and cockroaches. Molecular data (Chapter 2) supported the notion that bacteria in RIFA larvae are transient. The absence of specialized structures with obligate endosymbionts was evidence that bacteria in fourth-instar larvae were present because they were brought to the nest from the field and fed to the young. Only epithelial and muscle cells were found in the lining of guts of RIFA larvae. The gut lumen contained bacteria, fluids, and bolus. Fourth-instar larvae are believed to be the only members in a RIFA colony that can digest solid food. Such abilities may be due to glands in the gut that secrete digestive compounds instead of specialized gut organisms that facilitate the process like protozoans in termites.

Bacteria in the guts of fourth-instar larvae are derived exclusively from the diet and the environment, not from specialized bacteriocytes. Our data provided irrefutable evidence in regards to the sources of bacteria in RIFA fourth-instar larvae. Food and environmental sources supplied the bacteria previously identified in our PCR/sequencing 
work. Microscopy did not find bacteria in bacteriocytes or even bacteriocytes themselves. Bacteria were found in the lumen of the hindgut.

Though coadapted bacteria and specialized bacteriocytes were not found in the guts of fourth-instar larvae, such specialized organisms may be present elsewhere in the ant. Coadapted endosymbionts may be present in the hemolymph, fat body, or other organs in fourth-instar larvae. Adult ants may contain coadapted endosymbionts that help the colony survive in the wild by providing nutrients or other useful compounds. 


\section{CHAPTER 6}

\section{CONCLUSION}

My study included an assortment of culture-independent techniques, the primary one being 16S rDNA sequencing. Studies performed with antibiotics and microscopy supported the conclusion drawn from the $16 \mathrm{~S}$ rDNA sequencing work. The null hypothesis that fourth-instar larvae do not contain coadapted bacteria and that all the bacteria identified were environmental was supported in every case. Bacteria in the fourth-instar larvae were present because they were consumed with food sources or acquired through interactions with the environment. If not from the food or the environment where else would the ants have acquired their gut bacteria? From molecular data, a different list of bacteria from each colony with different branching and clustering among bacterial clades in the phylogenetic trees was found. Different bacterial diversity and evenness was found in all colonies, which provided evidence against the idea of the presence of obligate endosymbionts in RIFA fourth-instar larvae guts. One ant colony (Bogalusa) that had been exposed to two different rearing conditions (field versus lab) yielded two different lists of bacteria. Direct methods described above did not indicate the presence of obligate endosymbionts. Likewise, indirect approaches came up with the same results.

If the fire ants had obligate endosymbionts then clearing the guts should have a detrimental effect on them like what was observed by Jaffe et al. (2001) in C. pusillus. Clearing out endosymbionts with antibiotics increased mortality in C. pusillus. I tested three broad-spectrum antibiotics and found no significant differences in ant mortality when compared to the untreated controls. These results suggested that unlike C. pusillus, red imported fire ants do not have obligate endosymbionts otherwise the mortality of 
adult workers would have been affected. Following this method of study was light and electron microscopy. Unlike Sauer et al. (2002) who found bacteriocytes in carpenter ants I was unable to find bacteriocytes in the midgut epithelium of fire ants. With little similarities in bacteria inventories between colonies and no visual evidence of bacteriocytes I arrived at my conclusions. The microscopic observations provided irrefutable evidence that bacteriocytes were not present in fourth-instar RIFA larvae and that all identified bacteria were derived from the food or the environment.

The reason for the lack of obligate symbiosis may be due to diet. RIFA's diet consists of diverse food items. Workers also collect honeydew and will forage for sweets, proteins, and fats (Vinson and Sorenson, 1986). Fire ants acquire all their essential nutrients from their diet. Unlike termites, individuals of Tetraponera, and Camponotus floridanus, RIFA may not need specialized obligate symbionts to supply it with supplemental nutrients. RIFA gut bacteria communities are contributed by substances ingested from the environment.

Though coadapted bacteria and specialized bacteriocytes were not found in the guts of fourth-instar larvae, such specialized organisms may be present elsewhere in the ant. Coadapted symbionts may exist in other parts of the larvae's body or in other stages of development. However, the fourth-instar larvae remains the primary stage responsible for the digestion of solid food and the source of nutrients for the queen and adult workers through the production of chymotrypsin-like and elastase-like proteinases (Whitworth et al., 1998). In termite and carpenter ant examples, nutrients and enzymes that facilitate food digestion can be from obligate endosymbionts. However, based on our results, these proteinases are likely from the gut glands of RIFA. 
Transient bacteria can be taken up by the ants; can they also be transmitted to the environment and to each other? From a public health perspective RIFA may spread pathogens mechanically like roaches and pharaoh ants in nursing homes and hospitals in addition to being painful nuisance. Evidence for coadapted endosymbionts in RIFA was lacking, but further research into the transient nature of bacteria associated with these ants may be fruitful. Li et al. (2005) and Jouvenaz et al. (1996) were able to recover and culture live samples from ant guts. RIFA seem to have no discrimination when it comes to eating contaminated or uncontaminated food (Jouvenaz et al., 1996). Transgenic bacteria derived originally from natural environments may be engineered and introduced to the ant for control.

In addition to a possible public health application, our work may also be applied to the field of forensics. The transient nature of bacteria in RIFA larvae and the fact that bacteria can be identified culture-independently has been established. We also determined that the bacterial inventory can be completely changed in less than or equal to 82 days. Turnover rates may be significantly less than 82 days. More information in regards to the turnover rate of bacteria in guts may help detectives determine if a human corpse in an infested RIFA field was moved or not. Bacterial inventories on the corpse and in nearby RIFA colonies may help determine if the current location is indeed the real crime scene. As far fetched the idea may be, we should not discount the possibility, especially in places where RIFA are abundant. 


\section{REFERENCES}

Altschul, S.F., Gish, W., Miller, W., Myers, E.W., Lipman, D.J., 1990. Basic Local Alignment Search Tool. J. Mol. Biol. 215, 403-410.

Banjo, A.D., Lawal, O.A., Adeduji, O.O., 2005. Bacteria and fungi isolated from housefly (Musca domestica L.) larvae. Afr. J. Biotechnol. 4, 780-784.

Banks, W.A., Lofgren, C.S., Jouvenaz, D.P., Stringer, C.E., Bishop, P.M., Williams, D.F., Wojcik, P.D., Glancey, B.M., 1981. Techniques for collecting, rearing and handling imported fire ants. U.S. Dept. Agric. Tech. AAT-S-21. 9 p.

Beard, C.B., Durvasula, R.V., Richards, F.F., 1998. Bacterial symbiosis in arthropods and the control of disease transmission. Emerg. Infect. Dis. 4, 581-591.

Beard, C.B., Mason, P.W., Aksoy, S., Tesh, R.B. Richards, F.F., 1992. Transformation of an insect symbiont and expression of a foreign gene in the Chagas disease vector Rhodnius prolixus. Am. J. Trop. Med. Hyg. 46, 195-200.

Beatson, S.H., 1972. Pharaoh's ants pathogen vectors in hospitals. Lancet. 1, 425-427.

Bergey, D. H., 1984. Bergey's manual of systematic bacteriology: volume 1. Lippincott Williams and Wilkins, $964 \mathrm{p}$.

Bignell,D.E. 2000. Introduction to symbiosis. In: Termites: Evolution, Sociality, Symbioses, Ecology (eds, T. Abe, D.E. Bignell and M. Higashi), Kluwer Academic Publishers, Dordrecht, Netherlands, pp. 189-208.

Billen, J., Buschinger, A., 2000. Morphology and ultrastructure of a specialized bacterial pouch in the digestive tract of Tetraponera ants (Formicidae, Pseudomyrmecinae). Arthropod. Struct. Dev., 29, 259-266.

Blüthgen, N., Gebauer, G., Fiedler, K., 2003. Disentangling a rainforest food web using stable isotopes dietary diversity in a species-rich ant community. Oecologia. 137, 426435.

Bourtzis, K., Miller, T.A., 2003. Insect Symbiosis. CRC Press. p 347.

Breznak, J.A., Brill, W.J., Mertins, J.W., Coppel, H.C., 1973. Nitrogen fixation in termites. Nature. 244, 577-580.

Breznak, J.A., Brune, A., 1994. Role of microorganisms in the digestin of lignocellulose by termites. Ann Rev. Entomol. 39, 453-487.

Brose, U., Martinez, N.D.,Williams, R.J., 2003. Estimating species richness: sensitivity to sample coverage and insensitivity to spatial patterns. Ecology. 84, 2364-2377. 
Bussaban, B., Lumyong, P., Hyde, K.D., McKenzie, E.H.C., 2003. Three new species pf Pyricularia are isolated as zingiberaceous endophytes from Thailand. Mycologia. 95, 519-524.

Caetano, F.H., 1989. Endosymbiosis of ants with intestinal and salivary gland bacteria. In: Insect endocytobiosis, morphology, physiology, genetics, and evolution. Edited by W. Schemmler. CRC Press, Boca Raton, Fla. pp. 58-76.

Chao, A., 1984. Nonparametric-estimation of the number of classes in a population. Scand. J. Stat. 11, 265-270.

Chen, X., Li, S., Aksoy, S. 1999, Concordant evolution of a symbiont with its host insect species; molecular phylogeny of genus Glossina and its bacteriome-associated endosymbiont Wigglesworthia glossinidia. J. Mol. Evol. 48: 49-58.

Cheng, Q., Aksoy, S., 1999. Tissue tropism, transmission and expression of foreign genes in vivo in midgut symbionts of tsetse flies. Insect. Mol. Biol. 8,125-132.

Colwell, R. K., Mao, C.X., Chang, J., 2004. Interpolating, extrapolating, and comparing incidence-based species accumulation curves. Ecology. 85, 2717-2727.

Colwell, R.K., 1994-2004. EstimateS: statistical estimation of species richness and shared species from samples. (http://viceroy.eeb.uconn.edu/estimates). [Persistent URL: (http://purl.oclc.org/estimates).]

Derakshani, M., Lukow, T., Liesack, W., 2001. Novel bacterial lineages at the (sub)division level as detected by signature nucleotide-targeted recovery of 16S rRNA genes from bulk soil and rice roots of flooded rice microcosms. Appl. Environ. Microbiol. 67, 623-631.

Drancourt, M., Bollet, C., Carlioz, A., Martelin, R., Gayral, J.-P, Raoult, D., 2000. 16S ribosomal DNA sequence analysis of a large collection of environmental and clinical unidentifiable bacteria isolates. J. Clinical. Microbiol. 38, 3623-3630.

Dunn, A.K., Stabb, E.V., 2005 Culture-independent characterization of the microbiota of the ant lion Myrmeleon mobilis (Neuroptera: Myrmeleontidae). Appl. Environ. Microbiol. 71, 8784-8794.

Eldar, A., Goria, M., Ghittino, C., Zlotkin, A., Bercovier, H., 1999. Biodiversity of Lactococcus garvieae strains isolated from fish in Europe, Asia, and Australia. Appl. Environ. Microbiol. 65, 1005-1008.

Forns, X., Bukh, J., Purcell, R.H., Emerson, S.U., 1997. How Escherichia coli can bias the results of molecular cloning: preferential selection of defective genomes of hepatitis C virus during the cloning procedure. Proc. Natl. Acad. Sci. 94, 13909-13914. 
Gil, R., Silva, F.J., Zientz, E., Delmotte, F., González-Candelas, F., Latorre, A., Rausell, C., Kamerbeek, J., Gadau, J., Hölldobler, B., Van Ham, R.C.H.J., Gross, R., Moya, A., 2003. The genome sequence of Blochmannia floridanus: Comparative analysis of reduced genomes. Proc. Natl. Acad. Sci. 100, 9388-9393.

Hall, B.G. Phylogenetic trees made easy. Sinaur Associates, Inc. 2001.

Hughes, J.B., Hellmann, J.J., Ricketts, T.H., and Bohannan, B.J.M., 2001. Counting the uncountable: statistical approaches to estimating microbial diversity. Appl. Environ. Microbiol. 67, 4399-4406.

Ishikawa, H., 1989. Biochemical and molecular aspects of endosymbionts in insects. Int. Rev. Cytosol. 116, 1-45.

Jaffe, K., Caetano, F.H., Sanchez, P., Hernandez, J.V., Caraballo, L., Vitelli-Flores, J., Monsalve, W., Dorta, B., Lemoine, V.R., 2001. Sensitivity of ant (Cephalotes) colonies and individuals to antibiotics implies feeding symbiosis with gut microorganisms. Can. J. Zool. 79, 1120-1124.

Jouvenaz, D.P., Jeffrey, C., Lord, J.C., Undeen, A.H., 1996. Restricted ingestion of bacteria by fire ants. J. Invertebr. Pathol. 68, 275-277.

Klepzig, K.D., Moser, J.C., Lombardero, F.J., Hofstetter, R.W., Ayres, M.P., 2001. Symbiosis and competition: complex interactions among beetles, fungi and mites. Symbiosis 30, 83-96.

Kumar, S., Tamura, K., Nei, M., 2004. MEGA 3: Integrated Software for Molecular Evolutionary Genetics Analysis and Sequence Alignment. Briefings in Bioinformatics. 5, 150-163.

Lane, D.J., 1991. 16S/23S rRNA sequencing. In: E. Stackebrandt and M. Goodfellow (Eds.), Nucleic acid techniques in bacterial systematics, John Wiley and Sons, New York, NY, pp. 115-175.

Leser, T.D., Amenuvor, J.Z., Jensen, T.K., Lindecrona, R.H., Boye, M., Moller, K., 2002. Culture-independent analysis of gut bacteria: the pig gastrointestinal tract microbiota revisited. Appl. Environ. Microbiol. 68, 673-690.

Li, H.W., F. Medina, Vinson, S.B., Coates, C.J., 2005. Isolation, characterization, and molecular identification of bacteria from the red imported fire ant (Solenopsis invicta) midgut. J. Invert Pathol. 89, 203-209.

Liu, W., Marsh, T.L., Cheng, H., Forney, L.J., 1997. Characterization of microbial diversity by determining terminal restriction fragment polymorphism of genes encoding 16S rRNA. Appl. Environ. Microbiol. 63, 4516-4522.

Moran, N.A., Baumann, P., 2000. Bacterial endosymbionts in animals. Curr. Opin. Microbiol. 3, 270-275. 
Moreira, D.O., De Morais, V, Vieira-Da-Morta, O., De C. Campos-Farinha, A., Tonhasca Jr., A., 2005. Ants as carriers of antibiotic-resistant bacteria in hospitals. Neotrop.

Entomol. 34, 999-1006.

Northup, D.E., Barns, S.M., Yu, L.E., Spilde, M.N., Schelble, R.T., Dano, K.E., Crossey, L.J., Connolly, C.A., Boston, P.J., Natvig, D.O., Dahm, C.N., 2003. Diverse microbial communities inhabiting ferromanganese deposits in Lechuguilla and Spider caves.

Environ Microbiol. 5,1071-1086.

Nei, M., Kumar, S., 2000. Molecular evolution and phylogenetics, Oxford University Press, Oxford.

Pai, H.H., Chen, W.C., Peng, C.F., 2004. Cockroaches as potential vectors of nosocomial infections. Infect. Control. Hosp. Epidemiol. 25, 979-84.

Peloquin, J.J., Greenberg, L., 2003. Identification of midgut bacteria from fourth instar red imported fire ant larvae, Solenopsis invicta Buren (Hymenoptera : Formicidae). J. Agric. Urb. Entomol. 20, 157-164.

Saitou, N., Nei, M., 1987. The neighbor-joining method: A new method for reconstructing phylogenetic trees. Mol. Biol. Evol. 4, 406-425.

Sapp, J., 1994. Evolution by Association, Oxford University Press, Oxford.

Sauer, C., Dudaczek, D., Hölldobler, B., Gross, R., 2002. Tissue localization of the endosymbiotic bacterium "Candidatus Blochmannia floridanus" in adults and larvae of the carpenter ant Camponotus floridanus. Appl. Environ. Microbiol. 71, 8784-8794.

Schowalter, T., 2000. Insect ecology: an ecosystem approach, Academic Press, San Diego.

Shinzato, N., Muramatsu, M., Matsui, T., Watanabe, Y., 2005. Molecular phylogenetic diversity of the bacterial community in the gut of the termite Coptotermes formosanus. Biosci Biotechnol Biochem. 69, 1145-1155.

Stoll, S., Gadau, J., Gross, R., Feldhaar, H., 2006. Bacterial microbiota associated with ants of the genus Tetraponera. Biol. J. Linn. Soc. (accepted)

Urakawa, H.K. Kita-Tsukamoto, Ohwada, K., 1999. Microbial diversity in marine sediments from Sagami Bay and Tokyo Bay, Japan, as determined by 16S rRNA gene analysis. Microbiol. 145, 3305-3315.

Van Borm, S., Buschinger, A., Boomsma, J.J., Billen, J., 2002. Tetraponera ants have gut symbionts related to nitrogen-fixing root-nodule bacteria. Proc. R. Soc. Lond. 269, 20232027. 
Vinson, S.B., L. Greenberg., 1986. The biology, physiology, and ecology of imported fire ants. In S.B. Vinson, (Ed.) Economic Impacts and Control of Social Insects. Praeger, New York. pp. 193-226.

Vinson, S.B., Sorensen, A.A., 1986. Imported Fire Ants: Life History and Impact. The Texas Department of Agriculture. P. O. Box 12847, Austin, Texas 78711.

Walther, B.A., Morand, S., 1998. Comparative performance of species richness estimation methods. Parasitology. 116, 395-405.

Whitworth, S.T., Blum, M.S., Travis, J., 1998. Proteolytic enzymes from larvae of the fire ant, Solenopsis invicta isolation and characterization of four serine endopeptidases. J. Biol. Chem. 273, 14430-14434.

Wilkinson, T.L., 1998. The elimination of intracellular microorganisms from insects: an analysis of antibiotic-treatment in the pea aphid (Acyrthosiphon pisum). Comp. Biochem. Physiol. A. 119, 871-881.

Yurman, D., Dominguez-Bello, M.G., 1993. Bacteria present in the gut of two Neotropical Cephalotini ants, Cephalotes atratus and Zacryptocerus pussillus. Folia Microbiol. 38, 515-518. 


\section{APPENDIX: PRELIMINARY EXPERIMENTS}

My research protocols were not standardized until November 2004. Before then a lot of work was done to reduce contamination and to optimize a general PCR protocol that could be used with bacterial DNA templates. I started my work with culturedependent methods and adult RIFA workers. Culture-independent methods followed shortly. The protocol I used at the time was used to study termite DNA and proved to be inefficient in studies with ant bacteria. Once proper techniques were standardized I moved onto the fourth-instar larvae. Included in this appendix are early culture-dependent observations and an experiment involving whole RIFA larvae from a lab reared colony. 


\section{CULTURE-DEPENDENT OBSERVATIONS ON RED-IMPORTED FIRE ANT WORKERS}

August to September, 2004

Synopsis: Adult fire ant gut extracts were homogenized in saline buffer and spread on BHI agar plates. Plates were incubated aerobically and anaerobically at $30^{\circ} \mathrm{C}$ until colonies formed. The cultured bacteria were never sequenced and identified through the GenBank database. Most of the bacteria appeared to have been facultative anaerobes in that they could be grown in aerobic and anaerobic conditions. Bacteria cultured were predominantly Gram-negative rods with a few being Gram-positive cocci.

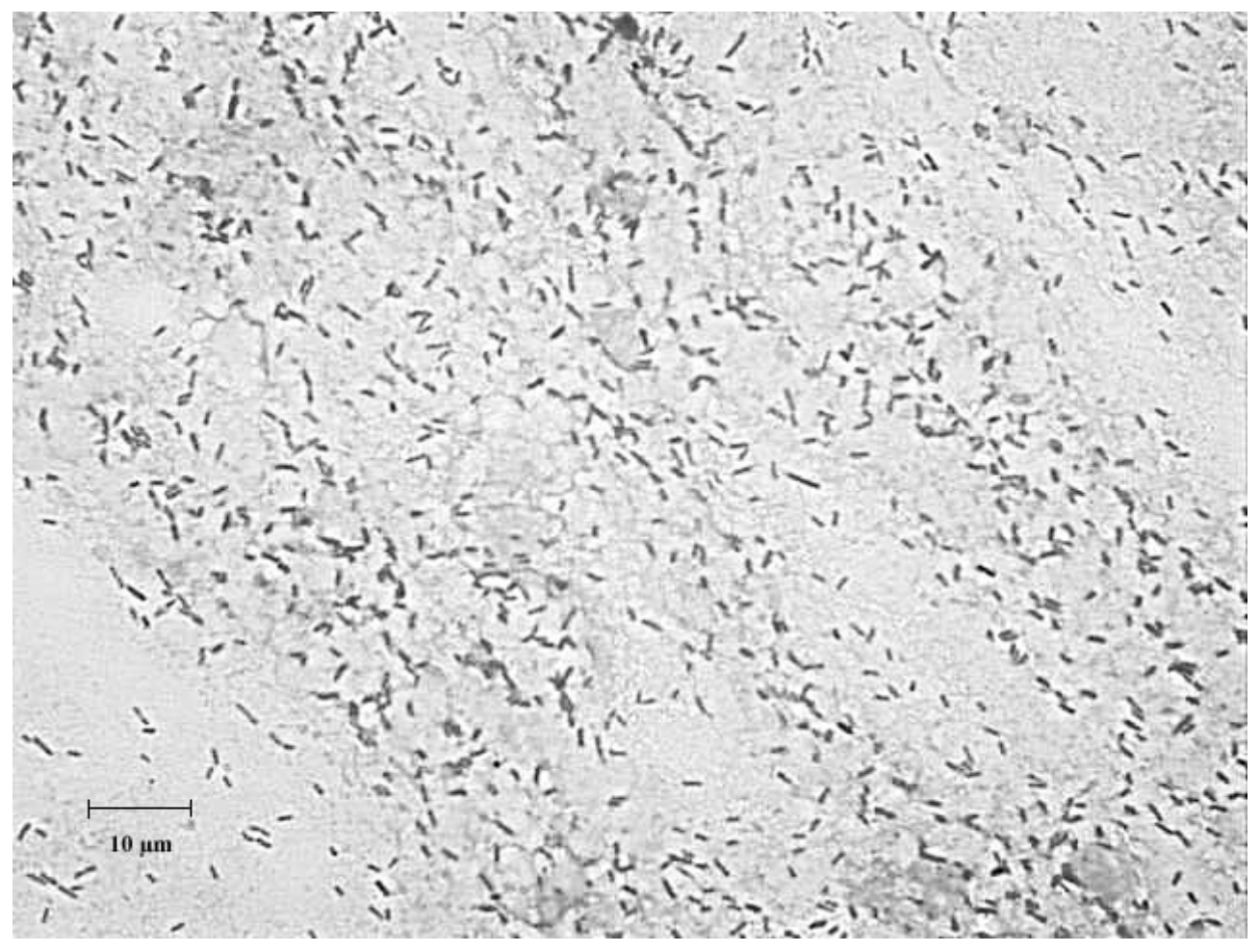

Gram-negative rods cultured from adult fire ant guts using BHI agar plates (aerobic and anaerobic conditions). 


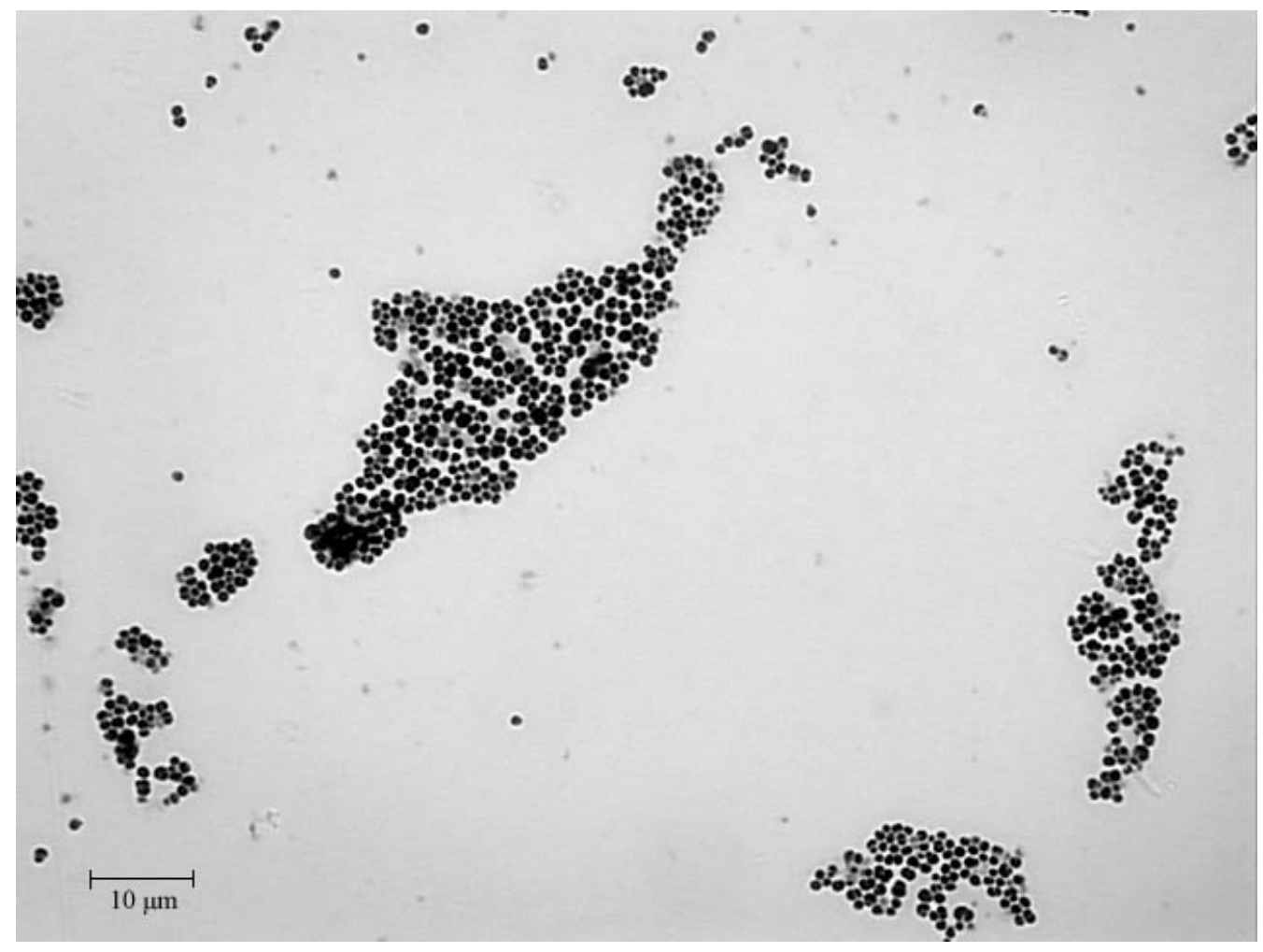

Gram-positive cocci cultured from adult fire ant guts using BHI agar plates (aerobic and anaerobic conditions). 


\section{CULTURE-DEPENDENT IDENTIFICATION OF BACTERIA IN FOURTH-INSTAR RED IMPORTED FIRE ANT LARVAE}

November, 2004

Synopsis: Larvae were surface sterilized and completely crushed into buffer. Serially diluted cultures were grown in BHI broth media and grown aerobically and anaerobically at $30^{\circ} \mathrm{C}$. Colonies with unique morphologies were taken out and their $16 \mathrm{~S}$ rDNA was extracted and analyzed to obtain the bacteria's identity.

The table below summarizes the bacteria I was able to culture with BHI media.

\begin{tabular}{|c|c|c|c|c|c|}
\hline $\begin{array}{l}\text { Isolation date/ } \\
\text { (time in } \\
\text { captivity) }\end{array}$ & Name & $\begin{array}{c}\text { GenBank } \\
\text { match }\end{array}$ & $\begin{array}{l}\text { Growth } \\
\text { condition }\end{array}$ & $\begin{array}{l}\text { Sample } \\
\text { Number }\end{array}$ & $\begin{array}{c}\text { Accession } \\
\text { number }\end{array}$ \\
\hline $10 / 28 / 04 /(16 \mathrm{~d})$ & Enterobacter aerogenes & $99 \%$ & Aerobic & 4,5 & AJ251468 \\
\hline $11 / 2 / 04 /(18 d)$ & Enterococcus avium & $99 \%$ & Anaerobic & 1,2 & AF061008 \\
\hline $11 / 2 / 04 /(18 d)$ & Erwinia sp. cryopeg & $98 \%$ & Aerobic & 3 & AY660693 \\
\hline $12 / 17 / 04$ / (66 d) & Proteus mirabilis & $99 \%$ & Anaerobic & 6 & AF008582 \\
\hline $12 / 17 / 04 /(66 \mathrm{~d})$ & Enterococcus avium & $99 \%$ & Anaerobic & 7 & AF061008 \\
\hline $12 / 17 / 04$ / (66 d) & Lactococcus garvieae M79 & $99 \%$ & $\begin{array}{l}\text { Anaerobic/Aer } \\
\text { obic }\end{array}$ & $8,9,10,12$ & AY699289 \\
\hline $12 / 17 / 04$ / (66 d) & Microbacterium sp. & $98 \%$ & Aerobic & 11 & AY040877 \\
\hline $2 / 11 / 05 /(125 \mathrm{~d})$ & Lactococcus garvieae M79 & $99 \%$ & $\begin{array}{c}\text { Anaerobic/Aer } \\
\text { obic }\end{array}$ & $\begin{array}{l}13,14,15,16,18 \\
20,21,22,23,26\end{array}$ & AY699289 \\
\hline $2 / 11 / 05 /(125 \mathrm{~d})$ & Enterococcus avium & $99 \%$ & Anaerobic & 17 & AF061008 \\
\hline
\end{tabular}




\section{CULTURE-INDEPENDENT IDENTIFICATION OF BACTERIA IN THE ENTIRE FOURTH-INSTAR LARVAE}

October to December, 2004

Synopsis: This experiment was my first attempt at studying the bacteria community in the fourth-instar larvae. I was unable to extract the guts without mutilating the whole larva yet so the entire larva was crushed like in the culture-dependent study described above. The ants were from a laboratory colony which had been established in the middle of October 2004. They had been in the lab 12 days before larvae were taken out and dissected. Unlike the studies that came after this one, which used all available fourthinstar larvae, only 25 larvae were used in this experiment. Many larvae remained in the colony and were not used in the experiment. The lab-reared colony from Bogalusa had two species in common with this bacteria inventory. Both inventories had Lactococcus garvieae isolate 36 and a species of Enterococcus faecalis. This experiment was done by Huei-Yang Ho, who was a student worker of mine at the time. 
NCBI Blast results for the 16S rRNA gene from 89 clones from a lab-reared colony from Baton Rouge. The name, accession numbers, closest matches in GenBank, and the number of clones identified to the species (category) are displayed.

Closest match in GenBank

Lactococcus garvieae isolate M79

Enterococcus avium 23

Pediococcus acidilactici B1104

Lactococcus garvieae isolate 36

Enterococcus faecalis SFL

Proteus mirabilis ATCC 29906

Enterococcus raffinosus 27

Enterococcus raffinosus NCIMB 12901

Pediococcus acidilactici B1104

Enterococcus hermanniensis LMG 13617

Uncultured bacterium 77133

Pediococcus pentosaceus ATCC 33316

Klebsiella sp. zmmo

Klebsiella pneumoniae ATCC 13886

Enterococcus sp. P7644

Klebsiella oxytoca ATCC 13182

Proteus mirabilis ATCC 29906

Uncultured bacterium D8D

Lactococcus garvieae isolate 36

Shigella boydii 3552-77

Enterococcus raffinosus 27

Selenomonas ruminantium S20

Pediococcus acidilactici DSM 20284

Nodularia sphaerocarpa CDAC1966/93-1

Klebsiella sp. zmmo

$\begin{array}{lll}\text { Accession\# } & \begin{array}{l}\% \text { identity to } \\ \text { closest match }\end{array} & \begin{array}{l}\text { Number } \\ \text { of } \\ \text { clones }\end{array}\end{array}$

$\begin{array}{lll}\text { AY699289 } & \geq 99 \% & 24 \\ \text { AF061008 } & \geq 99 \% & 12 \\ \text { AJ305322 } & \geq 99 \% & 11 \\ \text { AY946285 } & \geq 99 \% & 7 \\ \text { AY850358 } & \geq 99 \% & 6 \\ \text { AF008582 } & \geq 99 \% & 5 \\ \text { AF061003 } & \geq 99 \% & 3 \\ \text { Y18296 } & \geq 99 \% & 2 \\ \text { AJ305322 } & 98 \% & 2 \\ \text { AY396048 } & 98 \% & 2 \\ \text { AJ487025 } & \geq 99 \% & 1 \\ \text { AJ305321 } & \geq 99 \% & 1 \\ \text { U31075 } & \geq 99 \% & 1 \\ \text { AF228918 } & \geq 99 \% & 1 \\ \text { AJ276462 } & \geq 99 \% & 1 \\ \text { U78183 } & 98 \% & 1 \\ \text { AF008582 } & 98 \% & 1 \\ \text { AF253332 } & 97 \% & 1 \\ \text { AY946285 } & 97 \% & 1 \\ \text { AY696682 } & 92 \% & 1 \\ \text { AF061003 } & 98 \% & 1 \\ \text { AB017195 } & 91 \% & 1 \\ \text { AJ305320 } & 98 \% & 1 \\ \text { AF268018 } & 91 \% & 1 \\ \text { U31075 } & 98 \% & 1\end{array}$




\section{VITA}

Albert Lee was born on August 25, 1978 in Pittsburgh, Pennsylvania. His family moved to northern California shortly after his birth. He graduated from Henry M. Gunn High School in spring of 1996 and immediately began his college career at the University of California in Riverside, California. Albert received his Bachelor of Science degree in biology in the spring of 2000. Upon graduating with his bachelor's degree, he was accepted into a Master of Science program under the direction of Dr. Michael K. Rust at the same institution. Albert was awarded a Master of Science degree in entomology in the summer of 2002. Upon completion of the Master of Science of degree Albert worked as a research associate under Dr. Mir S. Mulla and the Coachella Valley Mosquito and Vector Control District. He began his doctoral studies in the Department of Entomology at Louisiana State University under the guidance of Dr. Linda Hooper-Bùi in the month of January of 2004. Albert was awarded his doctorate in December of 2007. 